Hydrol. Earth Syst. Sci. Discuss., 7, 5171-5212, 2010 www.hydrol-earth-syst-sci-discuss.net/7/5171/2010/ doi:10.5194/hessd-7-5171-2010

(c) Author(s) 2010. CC Attribution 3.0 License.
Hydrology and Earth System Sciences Discussions

This discussion paper is/has been under review for the journal Hydrology and Earth System Sciences (HESS). Please refer to the corresponding final paper in HESS if available.

\title{
Comparison between radar and rain gauges data at different distances from radar and correlation existing between the rainfall values in the adjacent pixels
}

S. Sebastianelli ${ }^{1}$, F. Russo ${ }^{1}$, F. Napolitano ${ }^{1}$, and L. Baldini ${ }^{2}$

${ }^{1}$ Department of Hydraulic, Transportations and Roads, "Sapienza" Univ. of Rome, Rome, Italy

${ }^{2}$ National Research Council, Institute of Atmospheric Sciences and Climate, Rome, Italy

Received: 30 June 2010 - Accepted: 2 July 2010 - Published: 30 July 2010

Correspondence to: S. Sebastianelli (stefano.sebastianelli@ uniroma1.it)

Published by Copernicus Publications on behalf of the European Geosciences Union.

\section{HESSD}

$7,5171-5212,2010$

Comparison between radar and rain gauges data at different distances

S. Sebastianelli et al.

\section{Title Page}

Abstract

Conclusions

Tables

14

4

Back

Full Screen / Esc

Printer-friendly Version

Interactive Discussion 


\section{Abstract}

Rainfall intensity data in pixels very far from radar are less correlated than values in pixels near the radar, because at far distances the width of a range-bin is comparable or bigger than the pixel width, so in a pixel there are one or just a few rainfall intensity

5 values. Vice versa, near the radar, there are many radar resolution bins which belong to a single pixel, so great correlation between rainfall intensity values for contiguous pixels is expected.

Moreover, the signal returned from precipitation at far distance from radar antenna can be due to a radar sample volume partially or completely filled with mixed phase or ice particles, or can be quite close to the minimum detectable signal.

All these phenomena can influence the goodness of rainfall estimates, introducing errors which increase as the distance from radar increases. The objective of this work is to characterize these errors as a function of the distance.

For this aim is possible to compare the rainfall data obtained by rain gauges at different distances from radar with rainfall radar data at the same distances, verifying the correlation existing between the rainfall values in the adjacent pixels and how the difference between radar and rain gauges data changes.

The radar data utilized in this work have been collected from the CNR-ISAC (Institute of Atmospheric Sciences and Climate of the National Research Council) Polar 55C radar in Rome Tor Vergata during 2008.

\section{Introduction}

Precipitation measurements are the starting point to study hydrological processes. They are utilized both for a better understanding of these processes and as input in hydrological simulation models indispensable to a correct territorial planning and to an
HESSD

$7,5171-5212,2010$

\section{Comparison between radar and rain gauges data at different distances}

S. Sebastianelli et al.

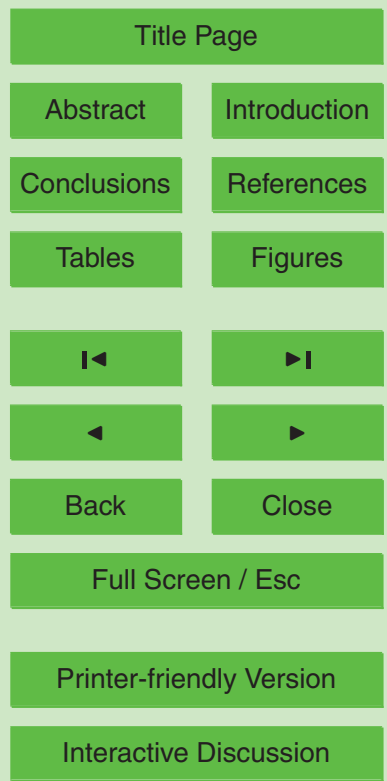


Radar and rain gauge are very different precipitation measuring devices. Radar samples precipitation in a volume aloft, estimating measurements related to scattering or propagation that are subsequently converted into rainfall intensity; the extension and height of this volume depending on the distance from radar and from the elevation 5 (usually small, but greater than $0^{\circ}$ ). Rain gauge makes a point measurement (if we compare its dimensions with the extension of precipitation) at ground, sampling with a delay the precipitation sampled aloft by the radar.

The radar is an electronic device that transmits an electromagnetic wave, which interacts with the objects in the atmosphere (typically raindrops, snowflakes, hailstones 10 or graupel), which reflect some of the intercepted power toward the radar (backscattering). The radar analyses the received echo, allowing to estimate important information with regard to scatterers, like position (azimuth and distance with respect to the radar) and properties of the backscattered echo (intensity, phase, polarization).

Rain gauges measurements are a major input of hydrological models. The accuracy 15 of flood estimates depends essentially on the rain gauges network density configuration and on the instrument precision (Maheepala et al., 2001). In fact the low spatial resolution of input of hydrological models is an important limit of hydrological prediction (Vaes et al., 2001). Therefore, to estimate the rainfall fields over an entire basin, rain gauges pointwise measurements need to be interpolated. However, different interpolation methods can to give significative differences in rainfall field estimates (Dirks et al., 1998).

Conversely, the weather radar is able to give, in real time and over a wide region, high spatial and temporal resolution rainfall intensity estimates, thus playing a significant role in the rainfall fields estimation and consequentially in the improvement of hydrographs simulation (Lopez et al., 2005); this fact allows obtaining an improvement of the hydrological models input data reliability, for correct simulations of run-off, which is necessary to flood forecasting and forewarning, with safety margin, and for drainage systems design (Clothier and Pegram, 2002).

\section{HESSD}

$7,5171-5212,2010$

\section{Comparison between radar and rain gauges data at different distances}

S. Sebastianelli et al.

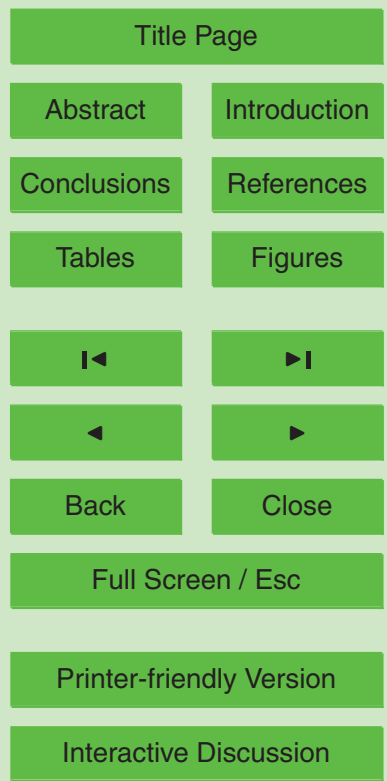


However, the spatial sampling of precipitation performed by radar is not uniform. As a consequence, the spatial structure of a rain field derived from weather radar measurements will be affected the way it sample precipitation and will be dependent on the distance from the radar and that influence the rainfall estimates, introducing an 5 error which increase as the distance from radar increases.

The objective of this work is to quantifying this error. For this aim is possible to compare the rainfall data obtained by rain gauges to different distances from radar with rainfall radar data to the same distances, verifying the correlation existing between the rainfall values in the adjacent pixels and analyzing the trend of the correlation between 10 rain gauges and radar measures when increasing the distance from radar (Sebastianelli et al., 2010).

Since rainfall data estimated by weather radar are smoothed in space, while rainfall data measured by rain gauges are both referred to a point and measured with a time delay as regards the radar, there are differences between radar data and rain gauges data. Usually radar estimates of rainfall are compared with rain gauges measures of precipitation and it is possible to give the mean square error of the radar-rain gauge comparison, the correlation coefficient and the biases of the comparison as statistical parameters of rainfall intensity (Zawadzki, 1975). The factors which produce discrepancies between radar and rain gauges data can be sources of random errors, as the error associated with the transformation from reflectivity to rain rate due to the variability of drop size distribution, or of systematic errors, as attenuation, or of range dependent errors too, associated with beam broadening and the increase in height with range of the sample volume.

Berenguer and Zawadzki $(2008,2009)$ have characterized the error structure considering the contributions of the range dependent errors, the effect of the error due to the $Z-R$ transformation and their interaction at nonattenuating wavelengths limiting to stratiform precipitation.

The single polarization radar-based estimates of rainfall are affected by source of uncertainty including radar miscalibration, attenuation, ground clutter, anomalous
HESSD

$7,5171-5212,2010$

\section{Comparison between radar and rain gauges data at different distances}

S. Sebastianelli et al.

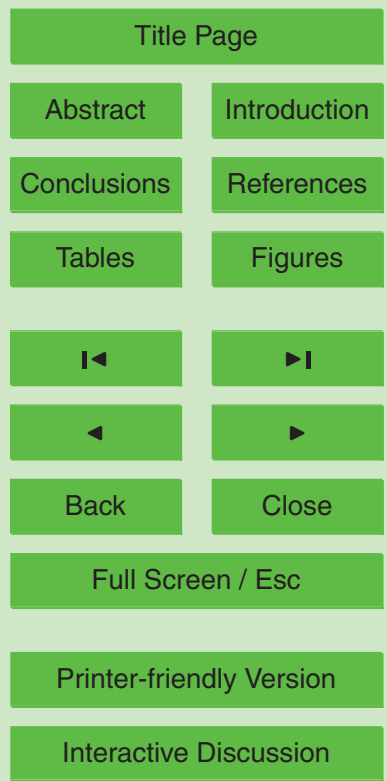


propagation, beam-blocking, variability of $Z-R$ relation, range degradation, vertical variability of the precipitation system, vertical air motion, precipitation drift and temporal sampling error (Villarini and Krajewski, 2010).

Therefore there is significatives uncertainty in rainfall amounts estimations, because

5 of sampling differences of the two devices, especially when short time intervals are considered: the correlation between radar and rain gauges data increases when the rainfall amounts are integrated over longer periods (Krajewski, 1995; Steiner et al., 1999; Russo et al., 2005; Sebastianelli et al., 2010).

In order to characterize errors between radar and raingauge correlation, correlation 10 coefficient, which is a measure of linear dependency between a pair of random variables, is used. The population correlation coefficient can be defined by choosing a pair of rainfall processes observed at two rain gauge locations. By considering pairs of rain gauges, it can be examinated the spatial dependence of rainfall through the analysis of the behaviour of Pearson's correlation coefficient in dependence on the distance between the two devices (Montesarchio et al., 2010).

To characterize rainfall fields by Pearson's correlation coefficient, Yoo and $\mathrm{Ha} \mathrm{(2007)}$ and $\mathrm{Ha}$ and Yoo (2007) investigated the influence of zero values; in fact, because of the intermittent nature of precipitation, the estimates of Pearson's correlation coefficient are affected by the presence of zero rainfall values. If $(X, Y)$ denote a pair of rainfall processes observed at two rain gauges locations, to analyse the three different kinds of possible pairs, which are: all pairs $(X \geq 0, Y \geq 0)$, all pairs except those with both values equal to zero $(X>0, Y=0)$ and $(X=0, Y>0)$ and $(X>0, Y>0)$, positive values at both rain gauges $(X>0, Y>0)$. The authors have found that the Pearson coefficient estimate is useful for the characterization of rainfall fields only considering 25 positive values at both rain gauges.

Montesarchio et al. (2010) have examined the time and space correlation between time series for different time scales separately for the rain gauge data set (considering the correlation between pairs of rain gauges) and the weather radar data set (considering the correlation between pixels). Then they are also evaluated the Pearson
HESSD

$7,5171-5212,2010$

\section{Comparison between radar and rain gauges data at different distances}

S. Sebastianelli et al.

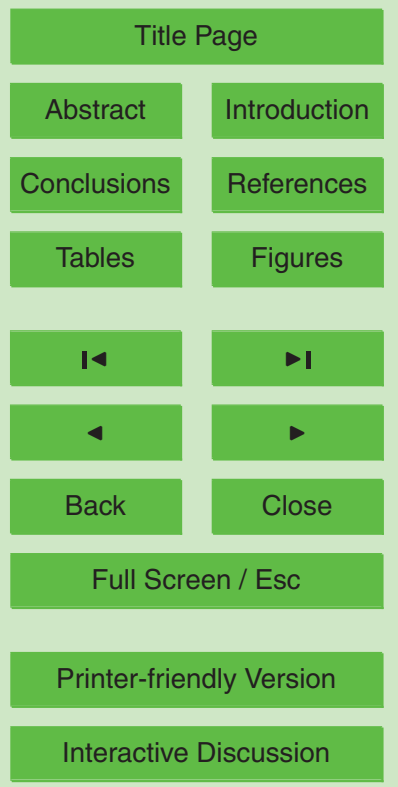


coefficient against absolute distances both for radar data and rain gauge found the same trend in the two cases; the Pearson coefficient decreases when increasing the absolute distances and, higher is the time scale, higher is the correlation. As shown by Yoo and $\mathrm{Ha}$ (2007), they are concluded that consider zero measurement in case of rain 5 gauge produce a high variability of inter-station correlation coefficients and somehow estimates not coherent with time scale aggregation.

In this work, to analyze the trend of the correlation between rain gauges and radar estimates as a function of the distance from radar, we eliminate the numerous couples of homologues components equal to zero of the rain gauges and radar vectors between 10 we are calculated the Pearson correlation coefficient, while, to verify the correlation existing between the rainfall values estimated by the radar in the adjacent pixels, we have not considered pixels with zero rainfall intensities values, because the numerous couples of adjacent pixels with rainfall intensities values equal to zero increase very much the correlation coefficient value, on the other hand the presence of a pixel with a 15 zero rainfall intensity value in many couples of adjacent pixels decreases the correlation coefficient value.

For this work, we have utilized rainfall intensity maps derived from radar reflectivity maps collected with the Polar 55C weather radar in the year 2008.

The paper is organized as follows. In the next section we explain the differences between radar and rain gauges quantitative measurements of precipitation. In Sect. 3, characteristics of the weather radar are described. In Sect. 4, we explain the assumed methodologies for the comparison between radar and rain gauges data process and for the correlation between the rainfall values in the adjacent pixels. In Sect. 5, we make the comparison between the rainfall values in the adjacent pixels and, finally, in Sect. 6

from radar.

\section{HESSD}

$7,5171-5212,2010$

\section{Comparison between radar and rain gauges data at different distances}

S. Sebastianelli et al.

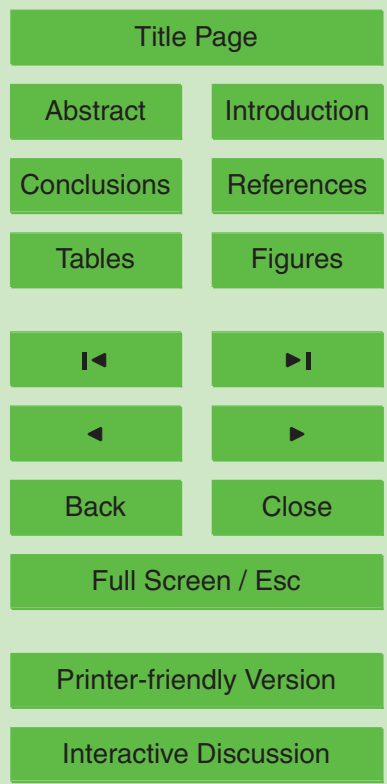




\section{Different radar and rain gauges quantitative measurements of precipitation}

A typical weather radar uses a pencil-beam antenna and the volume sampled increases with the distance, so the power intercepted by a meteorological target at a distance from antenna radar is only a part of the transmitted power because of the

5 radar beam tends to widen. Moreover, due to the earth curvature and to the fact that elevation angles greater than zero must be used to avoid beam interceptions by obstacles or relieves, the signal returned from precipitation at far distance from radar antenna can be due to a radar sample volume partially or completely filled with mixed phase or ice particles, or can be quite close to the minimum detectable signal, in fact, also at low elevations, the radar beam may sample above the clouds and does not intercept precipitation. On the other hand, being equal their reflectivity, only a part of the energy is scattered in the radar direction and the amount of energy collected by radar antenna, decreases as distance from radar increases. Therefore, the spatial sampling of precipitation performed by radar is not uniform and the same precipitation produces a return characterized by a signal to noise ration that decreases with increasing distance.

Besides, the minimum size of raindrops which radar can detect is smaller with decreasing wavelength but, on the other hand, the portion of signal absorbed by precipitation is larger for smaller wavelengths and, in the presence of precipitation, increases on average as the distance from radar increases. Considering typical weather radar wavelengths, it is known that S-band can be considered fairly immune from attenuation problems, whereas X-band is severely affected by attenuation. C-band, which is the typical choice of European operational weather radar, is affected by attenuation, but not as X-band. When the radar beam passes through an intense storm cell it weaken and therefore the rainfall intensity due to the cell is underestimated (Pegram and Clothier, cept the radar beam (Bringi and Chandrasekar, 2001). In case of total beam-blocking, rainfall intensity due to a rain cell beyond the obstacle cannot be estimates.

HESSD

$7,5171-5212,2010$

Comparison between radar and rain gauges data at different distances

S. Sebastianelli et al.

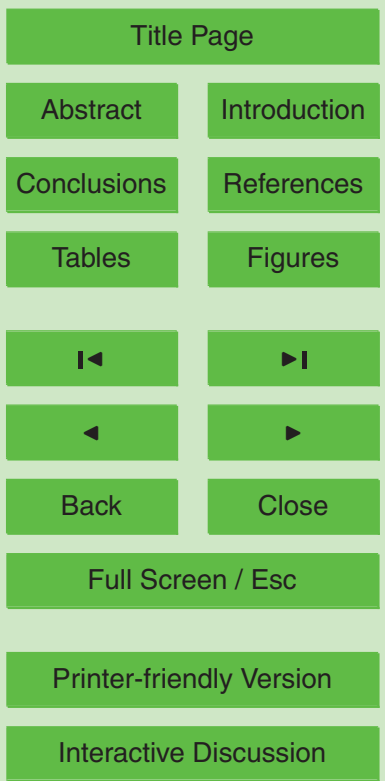


As a consequence, the spatial structure of a rain field derived from weather radar measurements will be affected the way it sample precipitation and will be dependent on the distance from the radar. All these effects can influence the goodness of rainfall estimates, introducing errors which increase as the distance from radar increases.

$5 \quad$ In radar hydrology, radar rainfall intensity maps are obtained by remapping radar polar pixels onto a Cartesian grid. It is expected that rainfall intensity data in pixels very far from radar are less correlated than rainfall intensity data in pixels near the radar, because of several reasons. At a long distance from radar the width of a range-bin is comparable or bigger than the pixel width, so in a pixel there are one or a few rain-

10 fall intensity values. In consequence the rainfall intensity values in a pixel is relative to range-bins very distant from the pixel contiguous, so there is not much correlation between the rainfall intensity values of contiguous pixels. Vice versa, near the radar, a single pixel is determined by many radar resolution volumes, so higher correlation between rainfall intensity values for contiguous range-bins of two adjacent pixels is expected; consequently, also rainfall intensity data of two adjacent pixels are correlated, because the rainfall in a considered pixel is the mean of the rainfall intensity values of the range-bins which belong to the considered pixel.

An objective of this work is to verify the correlation existing between the rainfall values in the adjacent pixels.

In the presence of wind or in the presence of trees or buildings, the rain gauge measures can be distorted, so the precipitation which is intercepted by the rain gauge can be appreciably different from the effective precipitation. The rain gauge observations are affected by errors due to different causes, like internal frictions and occasional imperfections of the rain gauge, reading errors, wind action which deflect the precipitation.

Since radar measures precipitation at a given height, rainfall is registered by the rain gauge below the radar sample volume with a delay with respect to the radar; the delay depends on the time needed to raindrops to precipitate. However the updraught can retard or block the precipitation, while the wind can transport the raindrops at a distance from the rain gauge. In some cases the rain gauge cannot measure any precipitation,
HESSD

7, 5171-5212, 2010

\section{Comparison between radar and rain gauges data at different distances}

S. Sebastianelli et al.

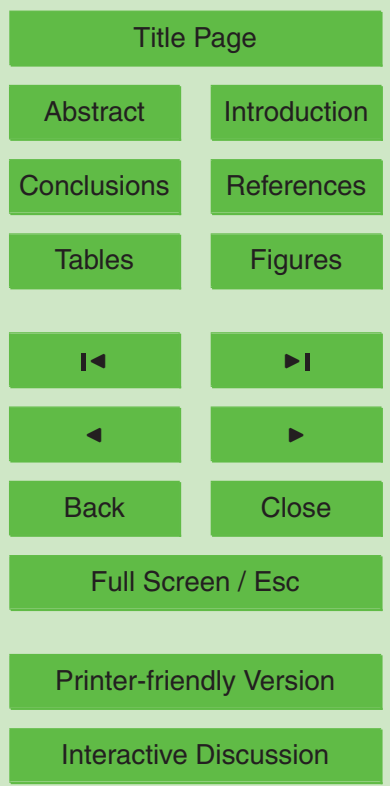


at the contrary the radar can detect the presence of the raindrops in the atmosphere. In addition, if the precipitation is formed by small diameter raindrops, they can evaporate in atmosphere before reaching the ground, and therefore they can be intercepted only by the radar but not by the rain gauge. Vice versa larger raindrops can drag along the 5 moisture present in the air, that cannot be detect by the radar and become larger during fall. In this condition the precipitation measured by the rain gauge can be greater than the precipitation measured by the radar.

The amount of water intercepted by the radar beam depends on sampling volume size. Therefore large sampling volumes determine decorrelation between rain rate de10 rived from radar data and rain rate measured by rain gauges. Moreover, higher is the radar beam, greater is the sampling volumes and the number of raindrops intercepted. As a consequence, since the radar samples all the raindrops into the sampling volume instantaneously, while the rain gauge collects a part of them with a delay, a decorrelation between rain rate measured by the rain gauge and rain rate estimated by the radar 15 is expected. Besides, for higher radar beam, during the falling, it is very probable both that the wind action distort the trajectory of the raindrops and that, because of coalescence, the raindrops combine or divide, so that the distribution of size at the gauge is different from that sampled by radar. These facts give further decorrelation between radar estimates and rain gauges measures of rainfall rate.

There is also a contribution to decorrelation between rain rate derived from radar data and rain rate measured by rain gauge due to the fact that the radar beam intercepts the freezing level. By observing the Figs. 8, 9, 10, 11 and 12, at distance of about $60 \mathrm{~km}$ from radar, the height of radar beam is over $2000 \mathrm{~m}$ above the sea level, at the elevation of $1.5^{\circ}$, therefore, especially in winter, the radar beam likely intercepts the freezing level. In case of stratiform precipitation, the air vertical motion velocity is lower than that of snow particles, so, in the most height layer of the clouds, the ice particles fall as soon as they are formed and they aggregate during the falling. Above the freezing level there are only ice particles, but under the freezing level there is a melting layer where there are both raindrops and ice particles which acquire a
HESSD

$7,5171-5212,2010$

\section{Comparison between radar and rain gauges data at different distances}

S. Sebastianelli et al.

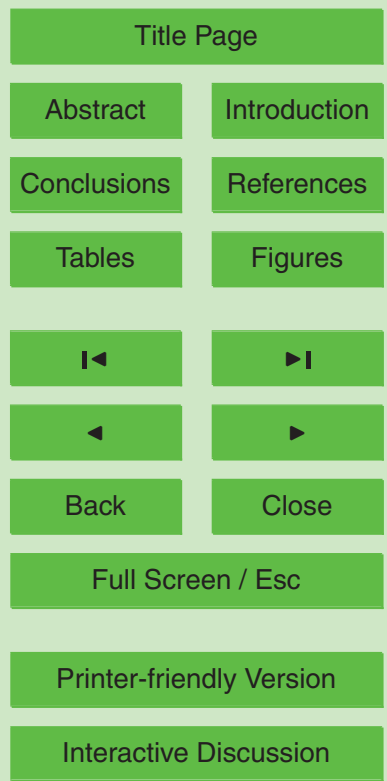


thin coat of water because they are melting. In this case radar overestimates the reflectivity factor and, consequently, the rainfall. In fact the ice particles width is greater than the raindrop width and the water layer on their surface reflects the radar signal. Therefore these particles reflect the radar signal as if the power was back-scattered 5 by very large raindrops with the same width of the ice particles. Since back-scattered power depends on the raindrop diameter sixth power, a few wet great ice particles are sufficient to overestimate the reflectivity factor, so a little number of great raindrops gives most of back-scattered power. The region where there are big wet snowflakes is frequently detected by weather radar through a very intense echo bright band in a 10 horizontal layer for about $0.5 \mathrm{~km}$ under the freezing level (Battan, 1970). Moreover, some wet ice particles persist over the melting layer, so the region characterized by the bright band extends as far as the temperature of $4-5^{\circ} \mathrm{C}$ under the melting layer (see Fig. 1).

Even if in convective events the bright band is not well defined, also in case of wet 15 hailstone, frequent at mid latitudes, at the elevation of $1.5^{\circ}$ (considered in this study) the radar overestimate the reflectivity. In fact the wet hailstone is formed both by raindrops and by hailstones covered by a water melting layer, like in the precedent case.

For the reasons mentioned above, radar and rain gauge can provide different quantitative measurements of precipitation and this work aims to analyses the trend of the correlation between rain gauge and radar measures when increasing the distance from radar.

\section{The Polar 55C weather radar}

\subsection{Features of Polar 55C weather radar}

The Polar $55 \mathrm{C}$ is a C-band $(5.6 \mathrm{GHz})$ Doppler dual polarized coherent weather radar with polarization agility managed by the Institute of Atmospheric Sciences and Climate of the National Research Council, Italy. The radar is located $15 \mathrm{~km}$ South-East of
HESSD

7, 5171-5212, 2010

\section{Comparison between radar and rain gauges data at different distances}

S. Sebastianelli et al.

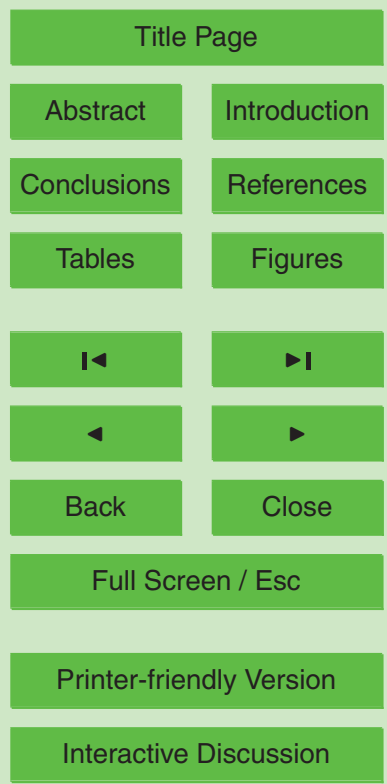


Rome, in the CNR (National Research Council) Tor Vergata area (lat. $41^{\circ} 50^{\prime} 24^{\prime \prime} \mathrm{N}$, Ion. $12^{\circ} 38^{\prime} 50^{\prime \prime} \mathrm{E}, 102 \mathrm{~m}$ a. s. I.). The radar employs a single offset antenna with $0.92^{\circ}$ azimuth beamwidth and $1.02^{\circ}$ elevation beamwidth. With its current configuration, Polar $55 \mathrm{C}$ can provide the commonly used polarimetric measurements, namely horizontally 5 reflectivity factor $(Z)$, differential reflectivity $\left(Z_{\mathrm{DR}}\right)$ and differential phase shift $\left(\Phi_{\mathrm{DP}}\right)$. Radar measurements are obtained by averaging 64 pulses transmitted with a $1200-\mathrm{Hz}$ pulse repetition frequency in range-bin spaced apart of $75 \mathrm{~m}$, up to $120 \mathrm{~km}$ away from the radar location (Gorgucci et al., 2002).

For the cases in point the scanning strategy adopted by Polar $55 \mathrm{C}$ prefigured the 10 cyclical repetition of eight sweeps all directions with constant elevation (Plan Position Indicators). Each 5 min 8 Plan Position Indicators (PPI) are acquired, each one with a different elevation angle, ranging from 0.5 to $7.5^{\circ}$. This work considers measurements collected at $1.5^{\circ}$ elevation. This elevation angle is selected considering two contrasting needs: on the one hand the need to increase the elevation value to minimize the ground-clutter problem, on the other hand the need to avoid that, at great distance from radar, the scanning beam would measure the water content into the clouds rather than water content into the precipitation (Gorgucci et al., 1995; Russo et al., 2005; Lombardo et al., 2006; Russo et al., 2006).

\subsection{From reflectivity data to rainfall intensity}

In this study rainfall estimates are obtained using radar reflectivity factor measurements.

The reflectivity data of Polar $55 \mathrm{C}$ are corrected for calibration bias by adding a correction factor to each recorded $Z$ value. This value is obtained during periodical maintenance by a static calibration procedure of radar receiver, which consists in directpower measured by the receiver (Bringi and Chandrasekar, 2001) and measurements of losses in passive microwave components.
HESSD

$7,5171-5212,2010$

\section{Comparison between radar and rain gauges data at different distances}

S. Sebastianelli et al.

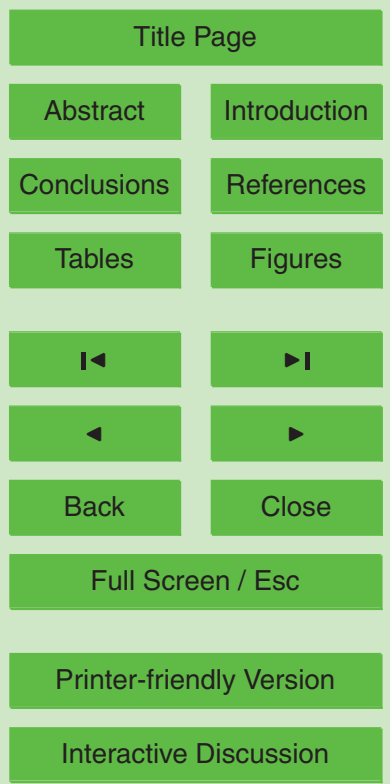


To use radar data for rain estimation two fundamental steps must be performed: distinction between meteorological signal and noise and between meteorological signal and ground clutter.

The weather radar transmits a power which is absorbed and then beamed isotrop5 ically in every direction by the raindrops. The back-scattered power by the raindrops is:

$P_{r}=\frac{C Z}{r^{2}}$

where $r$ is the distance of the raindrops from radar, $C$ is the radar constant and $Z$ is the reflectivity factor $\left(\mathrm{mm}^{6} \mathrm{~m}^{-3}\right)$.

The noise level is determinated in every radar reflectivity map supposing that at great distance, the radar, also with relatively low elevations like that we have utilized in this work, samples with a good chance in an atmospheric region above precipitation or clouds. Therefore the reflectivity factor measured at that distance derives from noise only. In this way the modal value in the last two range-bins can be chosen like a reference to determine the noise level at the receiver. The noise estimated as abovementioned is a constant power but, to distinguish between meteorological signal and noise, the noise is converted in reflectivity. The noise level at a distance $r$ from radar can be expressed by the Eq. (2) in the following way:

$Z_{\mathrm{s}}(r)=Z_{\mathrm{f}}+20 \log _{10}\left(\frac{r}{r_{\text {end }}}\right)$.

where in the left-hand $r_{\text {end }}$ is the maximum distance from radar, $Z_{\mathrm{f}}$ is the modal value of $Z_{\mathrm{h}}$ in the last two range-bins and the other addend is a corrective term due to the fact that the signal power decrease depending on the second power of the distance from radar (in linear scale). It is now possible to distinguish between meteorological signal and noise comparing along each record the values of $Z_{\mathrm{h}}$ at the distance $r$ with the relative values of $Z_{s}(r)$ and considering affected by noise the range-bins whose reflectivity does not exceed noise level by a threshold of $4 \mathrm{dBZ}$ introduced to esteem in 5182
HESSD

$7,5171-5212,2010$

Comparison between radar and rain gauges data at different distances

S. Sebastianelli et al.

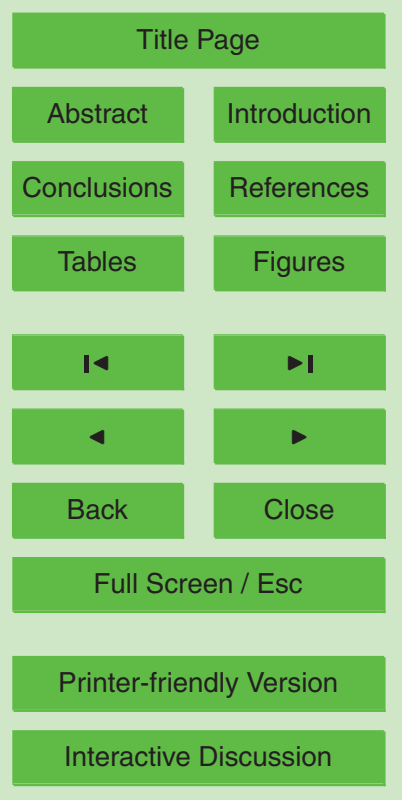

Interactive Discussion 
regard the noise fluctuations about median value. It should be noted that this method allows monitoring the noise level of the system.

Finally the reflectivity maps were purged from bins affected by ground clutter. The modality developed for the ground clutter removal is based on the existence of typi5 cal values for the standard deviations of the differential reflectivity $\sigma\left(Z_{\mathrm{DR}}\right)$ and of the differential phase $\sigma\left(\Phi_{\mathrm{DP}}\right)$ when the radar return is due to precipitation. In fact with meteorological echoes these standard deviations can be expressed by the width of the Doppler spectrum and the co-polar correlation coefficient about which is well-known the variation range characteristic of rainfall (Bringi and Chandrasekar, 2001; Lombardo 10 et al., 2006).

Another method to eliminate the effects of ground clutter is based on the use of Constant Altitude Plan Position Indicators (Pegram and Clothier, 1999). A CAPPI at the altitude of, say, $2 \mathrm{~km}$ above the ground level assures that there is almost not ground clutter and, besides, the bright band is usually above or at the $2 \mathrm{~km}$ level because of the high summer temperatures they are experienced in wet season in South Africa. Since the range at which the radar beam passes through the level situated $2 \mathrm{~km}$ above the ground is $67 \mathrm{~km}$, they are used data received beyond this range only for qualitative analysis; in fact these data are referred to a region within or above the melting layer.

In Fig. 2 the reflectivity map and the corresponding rainfall intensity map concern20 ing the same instant of data acquisition are shown. By a parametric algorithm, radar reflectivity is converted into rainfall intensity as (Gorgucci and Baldini, 2009):

$R=0.19055 \times 10^{\left(0.5358\left(\frac{z_{h}}{10}\right)\right)}$

where $Z_{\mathrm{h}}$ is the reflectivity factor (at horizontal polarization) and $R$ is the rainfall intensity (in $\mathrm{mm} \mathrm{h}^{-1}$ ). Coefficients of this algorithm are determined through simulations eters, a drop shape model, a fixed temperature and the distribution of canting angle. In this study, algorithms were derived choosing a normalized gamma DSD defined by its parameters varying in the range: $0.5<D_{\mathrm{o}}<3.5 \mathrm{~mm} ; 3<\log _{10} \mathrm{~N}_{\mathrm{w}}<5 ;-1<\mu<5$.
HESSD

$7,5171-5212,2010$

\section{Comparison between radar and rain gauges data at different distances}

S. Sebastianelli et al.

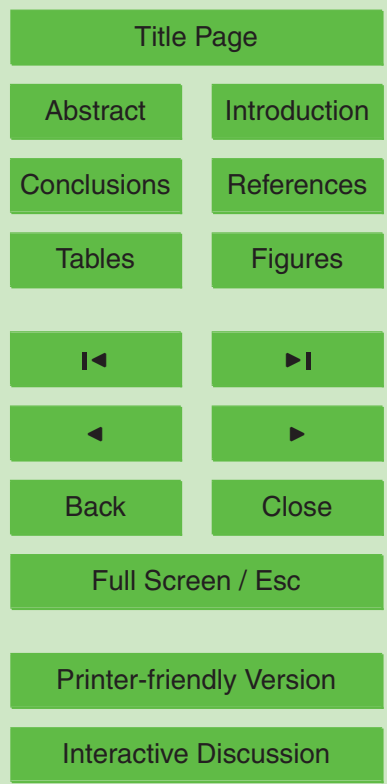

Interactive Discussion 
Further assumptions are: a) Pruppacher and Beard drop shape model (1970); b) canting angle distributed with mean $0^{\circ}$ and standard deviation $10^{\circ} ; \mathrm{c}$ ) temperature of $20^{\circ} \mathrm{C}$ (Bringi and Chandrasekar, 2001).

Finally, radar rainfall values are remapped onto a $1 \mathrm{~km}^{2}$ Cartesian grid, by assigning 5 to each pixel the mean of rainfall intensity estimated in the radar range-bins belonging to the pixel.

\section{Methodologies}

In this section, we describe the methodologies adopted to compare radar and rain gauge measurements and to estimate correlation between the rainfall values in the adjacent pixels. The database of rainfall intensity was collected during the 2008 year utilizing the Polar 55C weather radar.

\subsection{Methodologies for correlation between the rainfall values in the adjacent pixels}

To estimate the trend of the correlation between rainfall values in the adjacent pixels depending on distance from radar we have employed three different methods.

Considering a PPI collected by the radar during a rainfall event in the year 2008 and fixing a circumference centred on the radar site, we select the pixels which have the barycentre on this circumference and therefore are at the same distance from radar. For each of them we have considered the rainfall intensity observed and the rainfall intensity of one of the adjacent pixels. We then calculate the Pearson correlation coefficient of these data, which is relative to the distance considered. We have repeated the same procedure for every distance from radar until the edge of the scanning circle $(120 \mathrm{~km})$. For a single PPI, a Pearson correlation coefficient values vector, each of them relative to a particular distance, is obtained. Finally, after having obtained a vector of coefficient values for each PPI, we have calculated the arithmetic mean of the

\section{HESSD}

$7,5171-5212,2010$

Comparison between radar and rain gauges data at different distances

S. Sebastianelli et al.

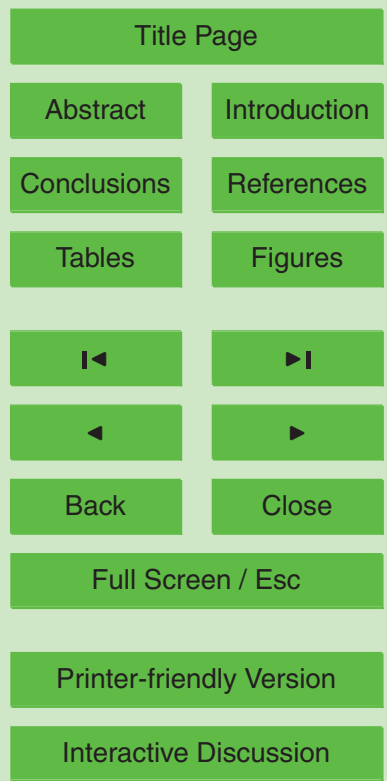


corresponding coefficients of each vector relative to the same distance and the result is a value relative to the whole of the rainfall event. For each rainfall event in the year 2008 a coefficient values vector was obtained. The single element of this vector is relative to a fixed distance and it is the arithmetic mean of the coefficients relative to 5 each PPI and to the same distance. This vector represents the trend of the correlation between the adjacent pixels when increasing the distance from radar.

A second method considers for each pixel at the same distance from radar, four adjacent pixels and computes the corresponding four correlation coefficients. Finally the arithmetic mean of the four coefficients was computed, obtaining a correlation coeffi10 cient relative to the distance considered and to the fixed PPI. After which we proceeded like in the first case, obtaining a correlation coefficient values vector for each PPI into the same event and then for each event of the year 2008.

In a third method, for a fixed PPI and at a distance from radar, the arithmetic mean of the rainfall intensity of the four pixels adjacent each pixel placed at the distance 15 from radar fixed is calculated. Therefore we have made two rainfall intensities values vectors. The Pearson correlation coefficient was calculated between these arithmetic means and the values of the pixels, relative to the distance specified and to the fixed PPI. Then we proceed like in the other two cases, calculating the correlation coefficient for each distance, obtaining a correlation coefficients vector relative to a single PPI. Finally we calculate the arithmetic mean of the homologue components of each vector obtained for a single PPI, calculating i.e. the correlation coefficients vector relative to the whole of the rainfall event. This vector represents the trend of the correlation between the rainfall intensities in the adjacent pixels when increasing the distance from radar.

\subsection{Methodologies for comparison between radar and rain gauges data}

The rain gauges we have considered are 38; whereof 22 located in the roman area: Acilia, Acqua Acetosa, Capannacce, Casilino, Cassiodoro, Eleniano, Eur, Falcognana, Flaminio, Fregene, Isola Sacra, La Storta, Monte Mario, Ostia, Ostiense, Ottavia, Ponte
HESSD

$7,5171-5212,2010$

\section{Comparison between radar and rain gauges data at different distances}

S. Sebastianelli et al.

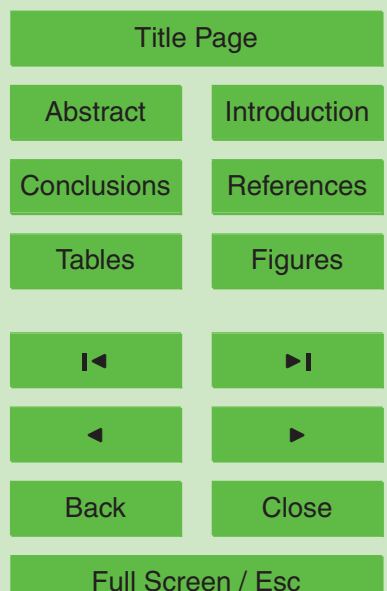

Full Screen / Esc

Printer-friendly Version

Interactive Discussion 
Galeria, Regillo, Roma Est, Roma Nord, Roma Sud and Via Marchi. We have considered also rain gauges located in the Marta river basin and in the Mignone river basin: Allumiere, Civitavecchia, Mignone, Rocca Respampani and Tarquinia. The other rain gauges utilized in this work are: Alatri, Borgo s. Maria, Bracciano, Castello Vici, Cervet5 eri, Poggio Mirteto, Ponte Felice, Posticciola, Rieti, Rocca Sinibalda and S. Martino. Figure 3 shows the case-study region, the rain gauges utilized in this work and their positions in relation to the Polar $55 \mathrm{C}$ location (in the centre of the scanning circle), the Rome ring road, the coast-line and the hydrographical network of the river Tiber. The rain gauges we are considered are reported in Table 1, with their distances (in $\mathrm{km}$ ) 10 from radar and the Cartesian coordinates (in $\mathrm{km}$ ) of the barycentre of the pixel where the single rain gauge belongs.

At first we have identified the pixels where are located the rain gauges considered, by calculating the Cartesian coordinates of the pixels barycentres and by knowing the Cartesian coordinates of the rain gauges, both respect Polar 55C. Then, for each rainthe rain gauge have measured contemporaneously. Therefore, having fixed a rainfall event and considered a single rain gauge, we have made a radar vector and a rain gauge vector. A radar vector component is the rainfall (in $\mathrm{mm}$ ) measured by the radar above the pixel where is located the rain gauge considered, while a rain gauge vector component is the rainfall (in $\mathrm{mm}$ ) which was measured by the rain gauge specified. The homologous components of the vectors are the rainfall which was measured by the radar and by the rain gauge at the same time. We have effectuated three analysis. In the first analysis, for the rain gauges which are located in Rome, the generic component of the two vectors is the rainfall which was precipitated in a period of $10 \mathrm{~min}$, while, for the other rain gauges, the component represents the rainfall which was precipitated in a period of $15 \mathrm{~min}$. In the second analysis, for all the rain gauges, the generic component of the two vectors is the rainfall which was precipitated in a period of $30 \mathrm{~min}$. Instead, in the last analysis, for all the rain gauges, the single component of the two vectors is the rainfall which was precipitated in a period of $1 \mathrm{~h}$. We have applied
HESSD

7, 5171-5212, 2010

\section{Comparison between radar and rain gauges data at different distances}

S. Sebastianelli et al.

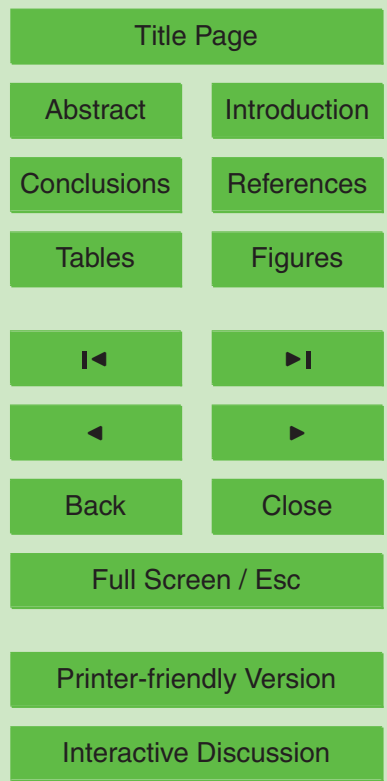


the same methodology for all the analysis. Selected a rainfall event, it was calculated the Pearson correlation coefficient between the radar vector and the rain gauge vector and that was performed for all the rain gauges. The same procedure was applied for the following rainfall events of the year 2008: 15 April 2008, 4-5 November 2008, 5 12-13 November 2008, 24 November 2008, 25-26 November 2008, 5 December 2008, 11-12 December 2008. As each rain gauge is situated at a different distance from the radar, for every rainfall event it was calculated a Pearson correlation coefficient for each distance. At last, for each rain gauge, we have made a rain gauge vector by linking together the rain gauge vectors we have made for every rainfall event. The resulting 10 vector components represent the rainfall values registered by the specified rain gauge in the whole of the year 2008. In the same way we have made a radar vector by concatenating the radar vectors we have made for every rainfall event. Finally we have calculated the Pearson correlation coefficient between the resulting radar vector and the resultant rain gauge vector, for each rain gauge, by obtaining the trend of the Pearson correlation coefficient when increasing the distance from radar related to the whole of the year 2008.

It must be noted that the rainfall values lower than $0.2 \mathrm{~mm}$ measured by the radar were considered equal to zero, because the rain gauges utilized in this work cannot measures a rainfall value lower than $0.2 \mathrm{~mm}$. Besides, if both the homologues components of the radar and the rain gauge vectors are equal to zero, they have been removed and they are not considered in the analysis, to avoid, if both the radar esteem a rainfall equal to zero and the rain gauge do not measures precipitation in the same temporal instant, the numerous couples of homologue components equal to zero increasing very much the Pearson correlation coefficient values, because of the inter25 mittent nature of rainfall.

\section{HESSD}

7, 5171-5212, 2010

\section{Comparison between radar and rain gauges data at different distances}

S. Sebastianelli et al.

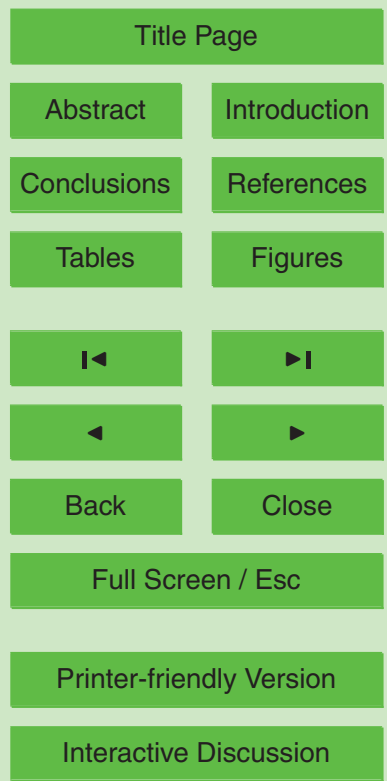




\section{Comparison between rainfall values in the adjacent pixels}

Figure 4 shows the trend of the correlation between adjacent pixels estimated with the three methods above-mentioned for the rainfall event of 12-13 November 2008. Each dot of the plots represents the mean of the values in a range of $2.5 \mathrm{~km}$.

5 A rain value in a generic pixel is similar to those in adjacent pixels, especially for stratiform rain events. However, if the considered pixel belong to a small convective rain cell, rain values in the adjacent pixels can be very bigger or smaller as to the selected value. Therefore, to estimate the trend of the correlation between adjacent pixels when increasing the distance from radar, is necessary to consider, for each selected pixel, a greater number of contiguous pixels. Besides, it can happen that the contiguous pixel can be affected by ground clutter that was not identified by the used algorithms. To mitigate the effect due to clutter contamination, it is convenient, before to estimate the Pearson correlation coefficients, to calculate the average of the rain values in all the adjacent pixels, for each considered pixel at the same distance from radar. For 15 these reasons we are chosen the third method to estimate the trend of the correlation between adjacent pixels when increasing the distance from radar. Figure 4 shows that the third method gives the highest values of the Pearson correlation coefficient and this fact is true for all of the rainfall events we have considered.

In the analysis we have not considered pixels with rainfall intensity values equal to 20 zero. In fact the numerous couples of adjacent pixels with rainfall intensity values equal to zero increase very much the correlation coefficient value. On the other hand the presence of a pixel with a rainfall intensity value equal to zero in many couples of adjacent pixels decreases the correlation coefficient value (Yoo and $\mathrm{Ha}, 2007$; $\mathrm{Ha}$ and Yoo, 2007).

25 The correlation between adjacent pixels as a function of distance was studied also in terms of differences between the seasons and relatively to the whole set of the year 2008. We have calculated the average of the corresponding elements of each correlation coefficients vector for each rainfall event of the same season, achieving the results showed in the Fig. 5.
HESSD

$7,5171-5212,2010$

Comparison between radar and rain gauges data at different distances

S. Sebastianelli et al.

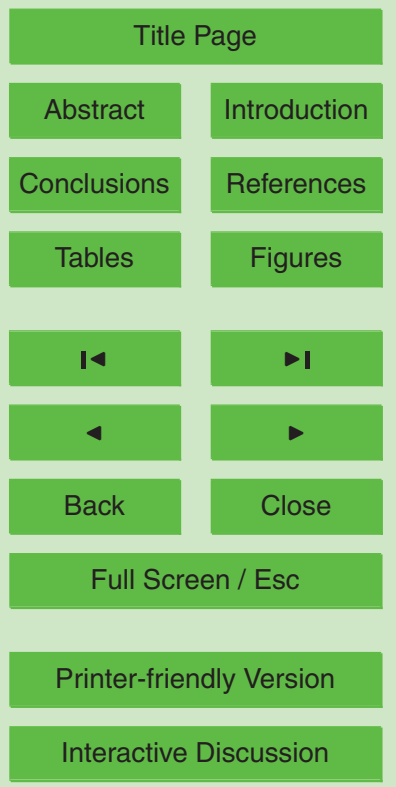

Interactive Discussion 
By observing the Fig. 4 we can note that the Pearson coefficient tends to decrease as the distance from radar increases and, also, that its smallest values are in the neighbourhood of the radar. In fact, near the radar, at the elevations we have considered, reflectivity values are affected by clutter due to terrain, buildings and other human5 made artefacts collected from antenna side lobes. Therefore near the radar there are many range-bins affected by ground clutter and probably not removed by the procedure based on standard deviation of polarimetric measurements. Since often ground clutter exhibits high decorrelation in space, for small distances from radar, the resulting Pearson correlation coefficient has the small values in Fig. 5. As explained in the intro10 duction, at a great distance from radar, the signal received by the radar from scatterers is so little because of geometric effect, attenuation due to precipitation, beam-blocking (in some areas), or sampling at layer above precipitation. As a consequence, the received signal is greatly influenced by noise which decorrelates the signal received by the radar.

15 That it was also performed for all the rainfall events in the year 2008, as showed in Fig. 6.

The curves we have obtained, which show the trend of the correlation between adjacent pixels, have many peaks, dues to the natural effects which occur when very intense rain cells in a mesoscale area decorrelate locally the meteorological signal.

$20 \quad$ In Fig. 5 each plot, representing the trend of the correlation between adjacent pixels and relatives to a specified season, is coupled with another plot which represents a typical PPI of that season. Always in Fig. 5 we can see that the Pearson correlation coefficient assumes lowest values in summer because of the natural effect due to isolated precipitation cells like those showed in the last plot in Fig. 5, whereas the other two plots on the right represent the typical PPI in autumn season and in the spring season, when the great rainfall intensity regions are most extensive and regular, therefore there is more correlation between adjacent pixels (Sebastianelli et al., 2010).

\section{HESSD}

$7,5171-5212,2010$

\section{Comparison between radar and rain gauges data at different distances}

S. Sebastianelli et al.

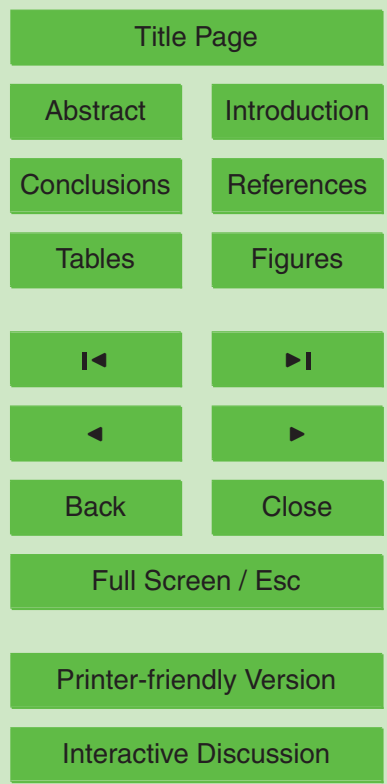




\section{Comparison between radar and rain gauge data at different distances from radar}

Figure 7 shows the trend of the Pearson correlation coefficient when increasing the distance from radar estimated, for the rainfall events of 11-12 December 2008 and of 5 December 2008, with the methodology specified in Sect. 3.2. The plots relatives to the same rainfall event in Fig. 7 are referred to different time intervals. Each point in Fig. 7 represents Pearson correlation coefficient value relatives to a single rain gauge, calculated between the vector of radar measurements and the corresponding rain gauge vector. Each rain gauge is located at a different distance from radar so every point corresponds only to a distance. The dots in green, black, blue and red represent values of the Pearson correlation coefficient calculated between two vectors whose components are the rainfall amounts measured (by the radar and the rain gauges) in a time interval of $10 \mathrm{~min}, 15 \mathrm{~min}, 30 \mathrm{~min}$ and $1 \mathrm{~h}$, respectively. Black dots refer to rain gauges which have rainfall amounts available each $15 \mathrm{~min}$, as those in the Marta river provides rainfall amounts available each $5 \mathrm{~min}$ ), while green dots refer to rain gauges which have rainfall amounts available each $10 \mathrm{~min}$, as those located in the roman area. Blue and red dots are referred to the whole of the rain gauges considered in this study.

By observing the Fig. 7 we can note that the Pearson correlation coefficient de20 creases when increasing the distance from radar, as showed by the black regression lines in the first four plots given for time intervals of $1 \mathrm{~h}$ and $30 \mathrm{~min}$; in fact, at great distance from radar, the radar measures and the rain gauges measures are very less correlated because of a several factors about which we have discuss in the introduction. For example the radar can samples above the clouds when the signal emit is very far from it otherwise, always at great distances, the raindrops maybe intercepted by the signal emit are some kilometres above the ground, therefore they precipitates in a long time, being collected by the rain gauge after a time. In this case the radar measures and the rain gauge measures are very decorrelate.
HESSD

$7,5171-5212,2010$

Comparison between radar and rain gauges data at different distances

S. Sebastianelli et al.

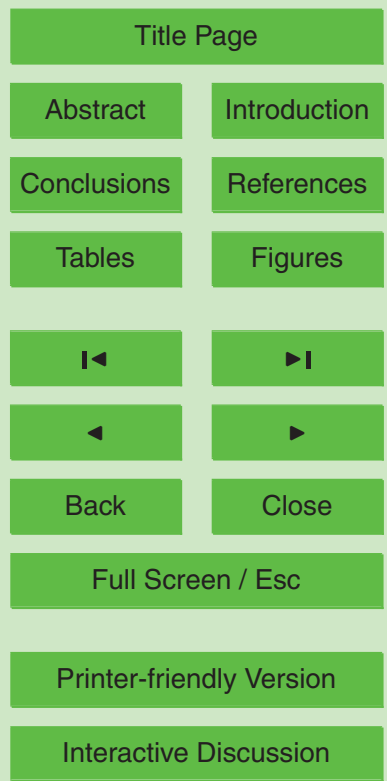


By comparing the plots in Fig. 7, we can also to note that, fixed a distance from radar, the Pearson correlation coefficient values increase as the time interval over which rainfall amounts are computed increases (Krajewski, 1995; Steiner et al., 1999; Russo et al., 2005; Montesarchio et al., 2010; Sebastianelli et al., 2010). In fact, in a large time 5 interval a rain gauge can collect raindrops that the radar have detected before a time above it, because in this time interval the raindrops are likely precipitated. Therefore, as discussed in the introduction, in relation to a large time interval, the radar measures and the rain gauge measures are more correlated than the same measures relative to a small time interval.

10 By observing the Fig. 7 we can see that the Pearson correlation coefficient assumes some low values for rain gauges located within $20 \mathrm{~km}$ from the radar, in the roman area, even for time intervals of $30 \mathrm{~min}$ or $1 \mathrm{~h}$. This effect is ascribed to the urban clutter, due to backscattering from buildings and other constructions which the radar main beam or its side lobes intercept in the neighbourhood of the radar. As a consequence, 15 urban clutter decorrelates radar and rain gauges measurements decreasing Pearson correlation coefficient.

Besides, Figs. 7 and 10 show that, fixed a rain gauge, the correlation between rain gauge measurements and radar estimates can also depend on the rainfall event considered. For example, considering rain gauges located in roman area, their measurements are usually correlate with radar estimates (in the absence of urban clutter), but, during some events, it is not true in the presence of temporary obstacles which produce ground clutter, or because the elevation angle is not always exactly equal to $1.5^{\circ}$, but it can changes (for example because of the wind action) and, since near the radar the radar beam is not so high, small variations of the elevation angle are sufficient so that the radar beam intercepts some obstacle, which produces a not meteorological signal at the receiver.

Figure 8 shows that, considering a rainfall event made by linking together all the events utilized in this work,

\section{HESSD}

$7,5171-5212,2010$

\section{Comparison between radar and rain gauges data at different distances}

S. Sebastianelli et al.

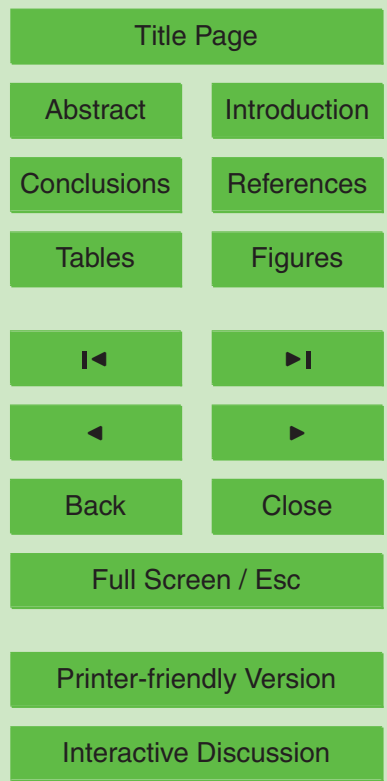


we can give the same comments given about the trend of the Pearson correlation coefficient showed in Fig. 7 for a single rainfall event.

Further to the comments done for the Figs. 7 and 8, Fig. 9 shows also the trend, when increasing the distance from radar, of the differences between Pearson correla5 tion coefficient values relative to different time aggregations, for the rainfall events of 12-13 November 2008, of 5 December 2008 and for the whole of the events utilized in this work; the plots in Fig. 9 show that by increasing the time interval utilized to calculate the rainfall values (in $\mathrm{mm}$ ) from $10 \mathrm{~min}$ up to $1 \mathrm{~h}$ or from $15 \mathrm{~min}$ up to $1 \mathrm{~h}$ (depending on the considered rain gauges), the corresponding increase of the Pearson correlation 10 coefficient, indicated in Fig. 9 by the differences $r_{60}-r_{10}$ represented by green dots and $r_{60}-r_{15}$ represented by black dots respectively, is greater close to the radar because of the lowest radar beam with respect to the rain gauges as explained in the introduction (Sebastianelli et al., 2010).

The single plots in Fig. 10 show the trend of the Pearson correlation coefficient with 15 increasing the distance from radar estimated for rainfall cumulated in different time intervals. The first plot concerns the rainfall event of 5 December 2008, the second plot is relative to the rainfall event of $11-12$ December 2008, the third plot was made considering the rainfall event of 25-26 November 2008 and the fourth plot is referred to the whole of the rainfall events utilized in this work.

The violet arrows in Fig. 10 shown that the Pearson correlation coefficient values relative to rain gauges localized in Fig. 15, for each time interval, are generally lower than Pearson coefficient values concerned rain gauges at comparable distances from radar because off the beam-blockage. But, in some rainfall events, rainfall measurements performed by a rain gauge situated in a cone of shade (due to beam-blocking) are correlated with radar estimates. That occurs if there are, between the two devices, some range-bins affected by ground clutter not removed by the removal algorithm, and if there is a very intense precipitation on the pixel where belong the rain gauge. In fact the reflectivity factor due to ground clutter is comparable with those due to an intense storm. Nevertheless, as showed in the last plot in Fig. 10 (down on the right),

HESSD

$7,5171-5212,2010$

\section{Comparison between radar and rain gauges data at different distances}

S. Sebastianelli et al.

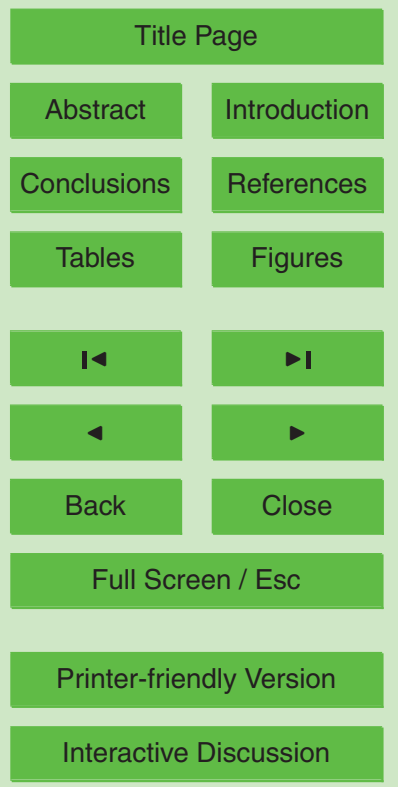


considering a rainfall event made by linking together all the events utilized in this work, measurements of rain gauges located into a cone of shade (showed by Fig. 15) are not much correlated with radar estimates.

Finally, we have compared the trend of the radar beam with the altimetrical profile 5 when increasing the distance from radar, to investigate the visibility of the radar beam for all the pixels where belong the range-bins utilized in this study.

The Digital Elevation Model (DEM) we have utilized is the Italy.bin file, with a pixel resolution of $800 \times 600 \mathrm{~m}$, which is product by Servizio Geologico Nazionale.

Each plot in Figs. 11, 12, 13 and 14 shows that there is not beam-blocking, because 10 the radar beam do not intercepts the altimetrical profile along the course from radar to rain gauge (unless anomalous propagations), therefore the radar can samples in the volume aloft above the rain gauge specified by the plot.

In the plots in Fig. 15 we can observe a total or partial radar beam-blocking caused by relieves located between the radar and the pixels where the rain gauges considered 15 by the plots belong. In cases of partial beam-blocking the radar data and the rain gauges data are very decorrelate or not correlate, in fact the radar underestimates the rainfall rate because only a part of the radar beam intercepts the raindrops, while in case of total beam-blocking the radar cannot measures in a sampling volume above the rain gauge.

\section{Conclusions}

For several reasons radar and rain gauge quantitative measurements of precipitation can be different. Rain gauge and radar are very different precipitation measuring devices: rain gauge makes a point measurements integrated in time at ground, while radar instantaneously samples precipitation in a volume aloft. Besides, since radar

measures precipitation at a given height, rainfall is registered by the rain gauge below the rain cell with a delay with respect to the radar which depends on the time needed to raindrops to precipitate. The rain gauge observations are affected by errors due to
HESSD

$7,5171-5212,2010$

\section{Comparison between radar and rain gauges data at different distances}

S. Sebastianelli et al.

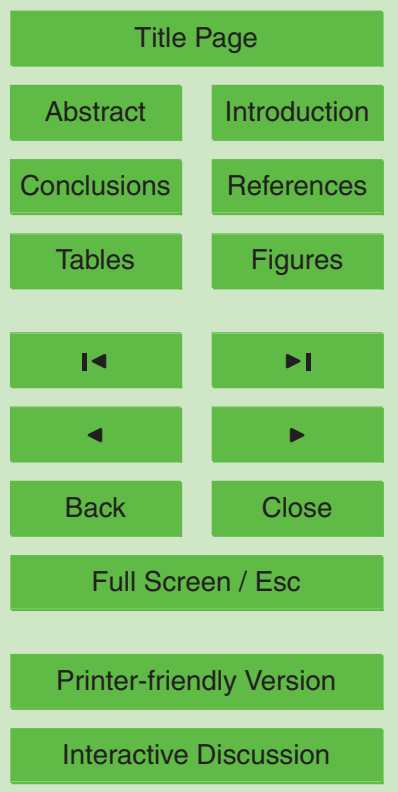


different causes, like internal frictions and occasional imperfections of the rain gauge, reading errors, presence of wind, trees or buildings that distorts the rain gauge measures. Radar measurements are affected by several sources of error, some of which determine errors that can be considered as depending on the distance from radar. In

this work we have showed that both the correlation between rain gauge and radar measures and the correlation between rainfall values in the adjacent pixels decreases when increasing the distance from radar. As shown by the results in Sect. 6, it is not possible to characterize discrepancies between measurements of the two instruments only as a function of distance from radar site. Other sources of error should be considered. 10 Nevertheless, the correlation coefficient exhibits a trend with the distance that must be accounted for when radar rainfall data are interpreted to study the spatial correlation of rainfall events.

Acknowledgements. The authors thank Eugenio Gorgucci of the Institute of Atmospheric Sciences and Climate of the National Research Council for interesting discussions and 15 suggestions.

\section{References}

Bringi, V. N. and Chandrasekar, V.: Polarimetric Doppler Weather Radar: Principles and Applications, Cambridge University Press, New York, USA, 648 pp., 2001.

Battan, L. J.: Radarmeteorologia, Zanichelli editore, Bologna, Italy, 1970.

Berenguer, M. and Zawadzki, I.: A Study af the Error Covariance Matrix of Radar Rainfall Estimates in Stratiform Rain, Weather Forecast., 23, 1085-1101, 2008.

Berenguer, M. and Zawadzki, I. A.: Study af the Error Covariance Matrix of Radar Rainfall Estimates in Stratiform Rain. Part II: Scale Dependence, Weather Forecast., 24, 800-811, 2009.

Clothier, A. and Pegram, G.: Space-time modelling of rainfall using the String of beads model: integration of radar and raingauge data, Water Research Commission, WRC Report No. 1010/1/02, Durban, South Africa, 166 pp., 2002.

\section{HESSD}

$7,5171-5212,2010$

\section{Comparison between radar and rain gauges data at different distances}

S. Sebastianelli et al.

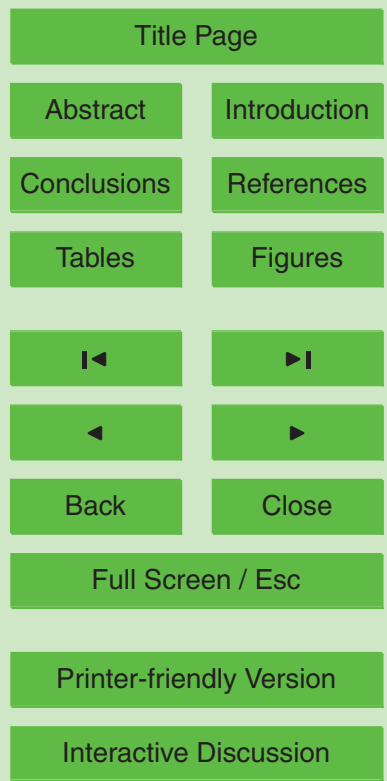


Dirks, K. N., Hay, J. E., Stow, C. D., and Harris, D.: High-resolution studies of rainfall on Norfolk Island. Part II: Interpolation of rainfall data, J. Hydrol., 208, 187-193, 1998.

Gorgucci, E. and Baldini, L.: An Examination of the Validity of the Mean Raindrop-Shape Model for Dual-Polarization Radar Rainfall Retrievals, Geoscience and Remote Sensing, IEEE Transactions on, vol. 47, 8, 2752-2761, doi: 10.1109/TGRS.2009.2017936, 2009.

Gorgucci, E., Baldini, L., and Volpi, A.: Polar 55C: an upgraded instrument for polarimetric radar research, Proc. of the 2nd European Conf. of Radar Meteorology ERAD, Delft, The Netherlands, 18-23 November 2002, 394-399, 2002.

Gorgucci, E., Scarchilli, G., and Chandrasekar, V.: Radar and surface measurements of rainfall during CaPE, J. Appl. Meteorol., 34, 1570-1577, 1995.

$\mathrm{Ha}, \mathrm{E}$. and Yoo, C.: Use of mixed bivariate distributions for deriving inter-station correlation coefficients of rainfall, Hydrol. Process., 21(22), 3078-3086, 2007.

Krajewski, W. F.: Rainfall estimation using weather radar and ground stations, in: Proceedings of the III Intemational Symposium on Weather Radars, San Paulo, Brazil, 1995.

15 Lombardo, F., Napolitano, F., and Russo, F.: On the use of radar reflectivity for estimation of the areal reduction factor, Nat. Hazards Earth Syst. Sci., 6, 377-386, doi:10.5194/nhess-6-3772006, 2006.

Lombardo, F., Napolitano, F., Russo, F., Scialanga, G., Baldini, L., and Gorgucci, E.: Rainfall estimation and ground clutter rejection with dual polarization weather radar, Adv. Geosci., 7, 127-130, doi:10.5194/adgeo-7-127-2006, 2006.

Lopez, V., Napolitano, F., and Russo, F.: Calibration of a rainfall-runoff model using radar and raingauge data, Adv. Geosci., 2, 41-46, doi:10.5194/adgeo-2-41-2005, 2005.

Maheepala, U. K., Takyi, A. K., and Perera, B. J. C.: Hydrological data monitoring for urban stormwater drainage systems, J. Hydrol., 245, 32-47, 2001.

Montesarchio, V., Russo, F., Napolitano, F., Lombardo, F., and Baldini, L.: Study on the rainfall dependence structure using radar and rain gauge data, in: Proceedings of the International Workshop Advances in statistical hydrology, Taormina, Italy, 23-25 May 2010, 24, 2010.

Pegram, G. and Clothier, A.: High resolution space-time modelling of rainfall: the "String of beads" model, Water Research Commission, Durban, South Africa, WRC Report No. $30 \quad$ 752/1/99, 115 pp., 1999.

Pruppacher, R. and Beard, K. V.: A wind tunnel investigation of the internal circulation and shape of water drops falling at terminal velocity in air, Q. J. Roy. Meteor. Soc., 96, 247-256, 1970.

\section{HESSD}

7, 5171-5212, 2010

\section{Comparison between radar and rain gauges data at different distances}

S. Sebastianelli et al.

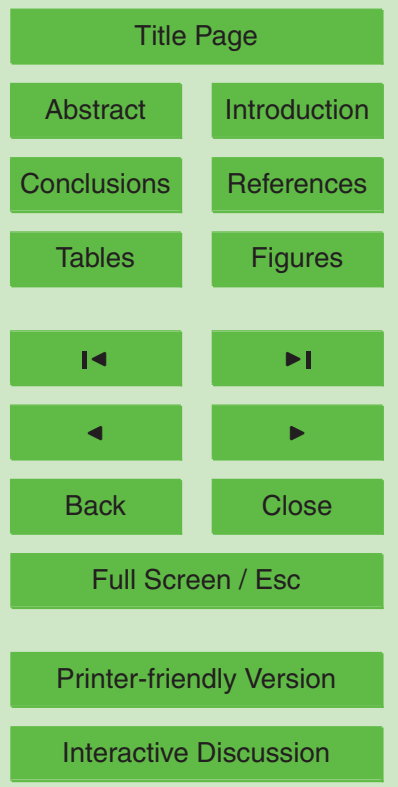


Russo, F., Lombardo, F., Napolitano, F., and Gorgucci, E.: Rainfall stochastic modelling for runoff forecasting, Phys. Chem. Earth, 31(18), 1252-1261, 2006.

Russo, F., Napolitano, F., and Gorgucci, E.: Rainfall monitoring systems over an urban area: the city of Rome, Hydrol. Process., 19(5), 1007-1019, 2005.

5 Sebastianelli, S., Russo, F., Napolitano, F., and Baldini, L.: Comparison between radar and rain gauges data at different distances from radar and correlation existing between the rainfall values in the adjacent pixels, in: Proceedings of the International Workshop Advances in statistical hydrology, Taormina, Italy, 23-25 May 2010, 31, 2010.

Steiner, M., Smith, J. A., Burges, S. J., Alonso, C. V., and Darden, R. W.: Effect of bias adjustment and rain gauge data quality control on radar rainfall estimation, Water Resour. Res., 35(8), 2487-2503, 1999.

Vaes, G., Wt1lems, P., and Berlamont, J.: Rainfall input requirements for hydrological calculations, Urban Water J., 3, 107-112, 2001.

Villarini, G. and Krajewski, W. F.: Review of the different sources of uncertainty in single polar15

ization radar-based estimates of rainfall, Surv. Geophys., 31(1), 107-129, 2010.

Yoo, C. and Ha, E.: Effect of zero measurements on the spatial correlation structure of rainfall, Stoch. Env. Res. Risk. A., 21(3), 287-297, 2007.

Zawadzki, I.: On radar-rain gauge comparison, J. Appl. Meteorol., 14, 1430-1436, 1975.

\section{HESSD}

$7,5171-5212,2010$

Comparison between radar and rain gauges data at different distances

S. Sebastianelli et al.

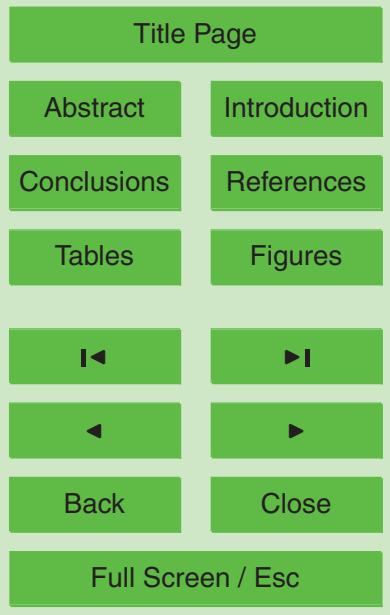

Printer-friendly Version

Interactive Discussion 
Table 1. Rain gauges considered in the analysis, their distances (in $\mathrm{km}$ ) from radar and Cartesian coordinates (in $\mathrm{km}$ ) of the barycentre of the pixels where belong the rain gauges.

\begin{tabular}{|c|c|c|c|}
\hline Rain gauge & Distance from radar & Abscissa & Ordinate \\
\hline Acilia & 23.269 & -22.5 & -7.5 \\
\hline Acqua Acetosa & 16.647 & -12.5 & 11.5 \\
\hline Alatri & 60.631 & 58.5 & -14.5 \\
\hline Allumiere & 70.719 & -60.5 & 37.5 \\
\hline Borgo s. Maria & 43.972 & 12.5 & -42.5 \\
\hline Bracciano & 48.854 & -38.5 & 30.5 \\
\hline Capannacce & 11.139 & -0.5 & 11.5 \\
\hline Casilino & 8.944 & -8.5 & 3.5 \\
\hline Cassiodoro & 16.712 & -14.5 & 7.5 \\
\hline Castello Vici & 41.780 & -29.5 & 29.5 \\
\hline Cerveteri & 48.218 & -44.5 & 19.5 \\
\hline Civitavecchia & 76.965 & -70.5 & 30.5 \\
\hline Eleniano & 12.343 & -10.5 & 5.5 \\
\hline Eur & 12.621 & -12.5 & -1.5 \\
\hline Falcognana & 11.237 & -7.5 & -8.5 \\
\hline Flaminio & 24.578 & -15.5 & 19.5 \\
\hline Fregene & 38.092 & -37.5 & 4.5 \\
\hline Isola Sacra & 35.347 & -34.5 & -7.5 \\
\hline La Storta & 28.889 & -21.5 & 18.5 \\
\hline Mignone & 81.554 & -70.5 & 41.5 \\
\hline Monte Mario & 19.785 & -16.5 & 10.5 \\
\hline Ostia & 32.184 & -30.5 & -11.5 \\
\hline Ostiense & 14.139 & -13.5 & 4.5 \\
\hline Ottavia & 23.371 & -19.5 & 13.5 \\
\hline Poggio Mirteto & 46.374 & 2.5 & 46.5 \\
\hline Ponte Felice & 58.861 & -13.5 & 57.5 \\
\hline Ponte Galeria & 24.584 & -24.5 & -0.5 \\
\hline Posticciola & 50.070 & 25.5 & 43.5 \\
\hline Regillo & 8.593 & 7.5 & 3.5 \\
\hline Rieti & 65.209 & 20.5 & 61.5 \\
\hline Rocca Respampani & 84.830 & -57.5 & 62.5 \\
\hline Rocca Sinibalda & 55.413 & 23.5 & 50.5 \\
\hline Roma est & 10.804 & -5.5 & 9.5 \\
\hline Roma nord & 18.564 & -12.5 & 13.5 \\
\hline Roma sud & 18.377 & -18.5 & -1.5 \\
\hline S. Martino & 61.201 & 29.5 & 53.5 \\
\hline Tarquinia & 88.131 & -73.5 & 48.5 \\
\hline Via Marchi & 13.892 & -10.5 & 9.5 \\
\hline
\end{tabular}

HESSD

$7,5171-5212,2010$

Comparison between radar and rain gauges data at different distances

S. Sebastianelli et al.

\section{Title Page}

\section{Abstract}

Introduction

Conclusions

References

Tables

Figures

14
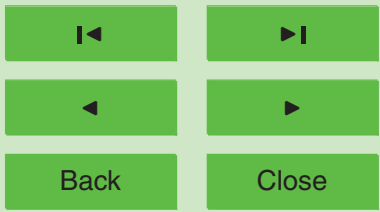

Back

Full Screen / Esc

Printer-friendly Version

Interactive Discussion 


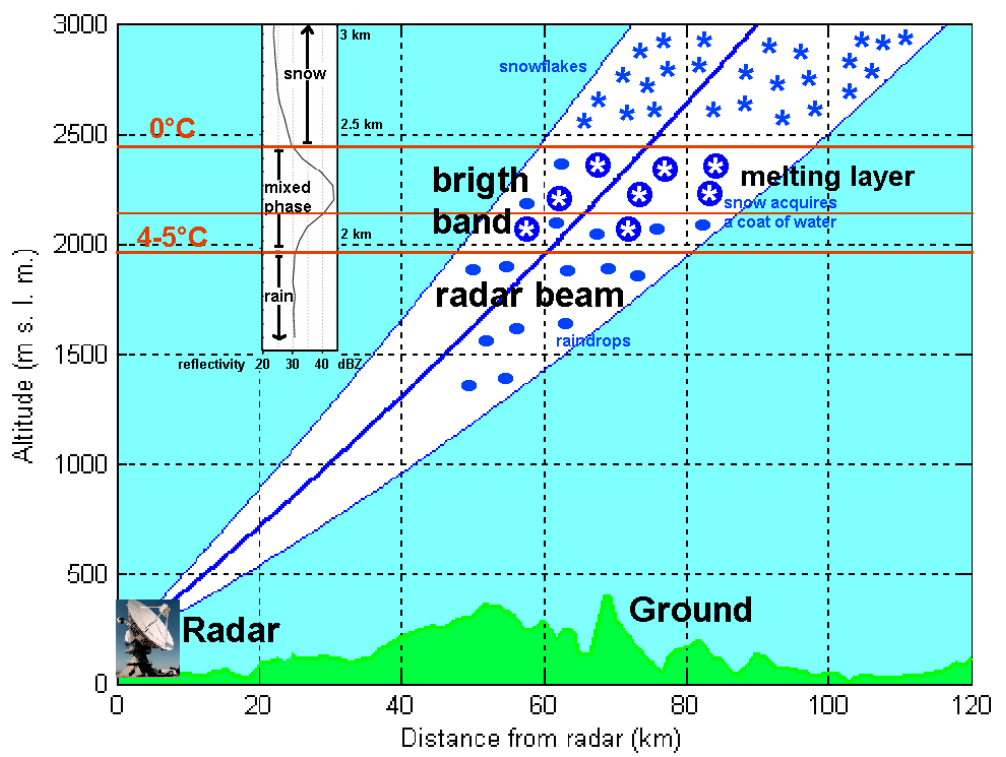

Fig. 1. Example of bright band dues to mixed phase.

\section{HESSD}

7, 5171-5212, 2010

Comparison between radar and rain gauges data at different distances

S. Sebastianelli et al.

\section{Title Page}

\section{Abstract}

Introduction

Conclusions

References

Tables

Figures

14

4

Back

\section{Full Screen / Esc}

Printer-friendly Version

Interactive Discussion 


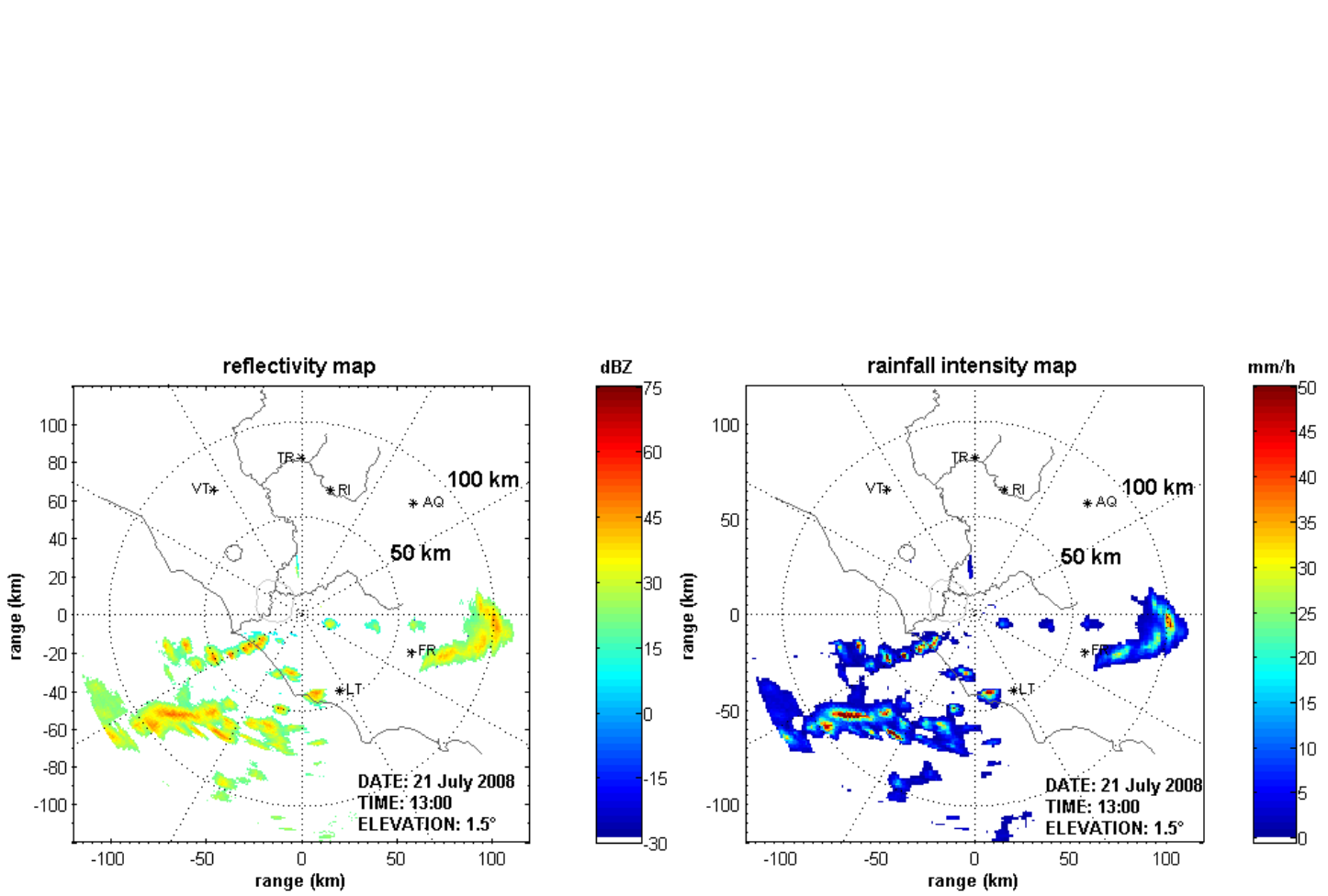

\section{HESSD}

7, 5171-5212, 2010

Comparison between radar and rain gauges data at different distances

S. Sebastianelli et al.

Title Page

Abstract

Conclusions

\section{Tables}

14

$\triangleleft$

Back

Full Screen / Esc

Printer-friendly Version

Interactive Discussion 


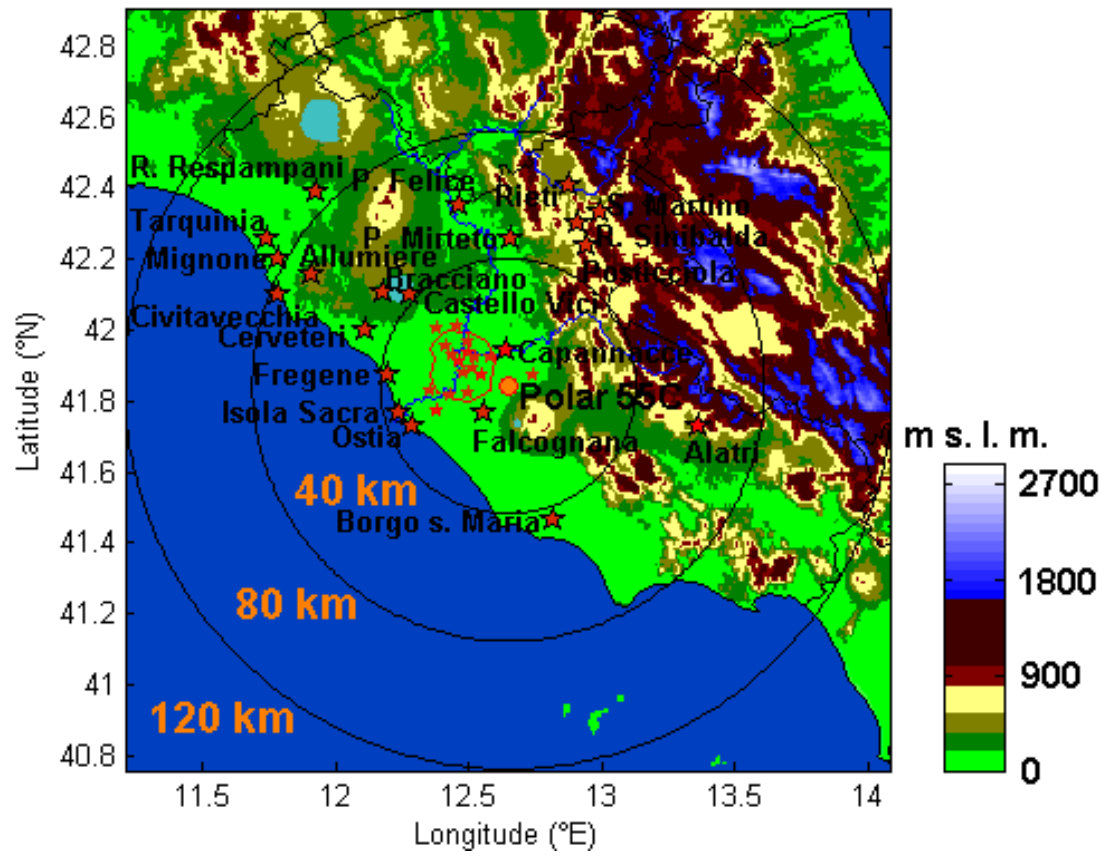

HESSD

$7,5171-5212,2010$

Comparison between radar and rain gauges data at different distances

S. Sebastianelli et al.

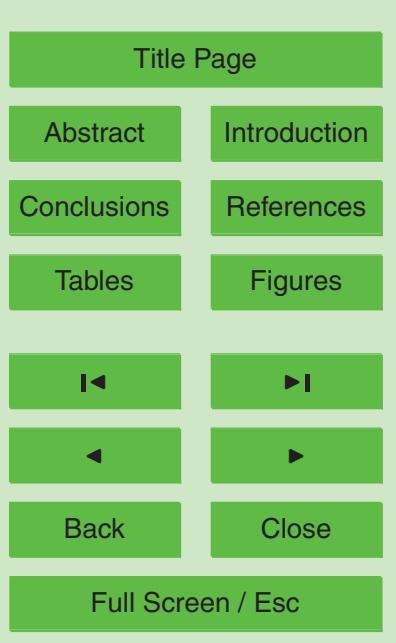

Fig. 3. Case-study region and rain gauges positions (in red) respect Polar $55 \mathrm{C}$ location (in orange, in the centre of the scanning circle), the Rome ring road, the coast-line and the hydrographical network of the river Tiber.

Printer-friendly Version

Interactive Discussion 

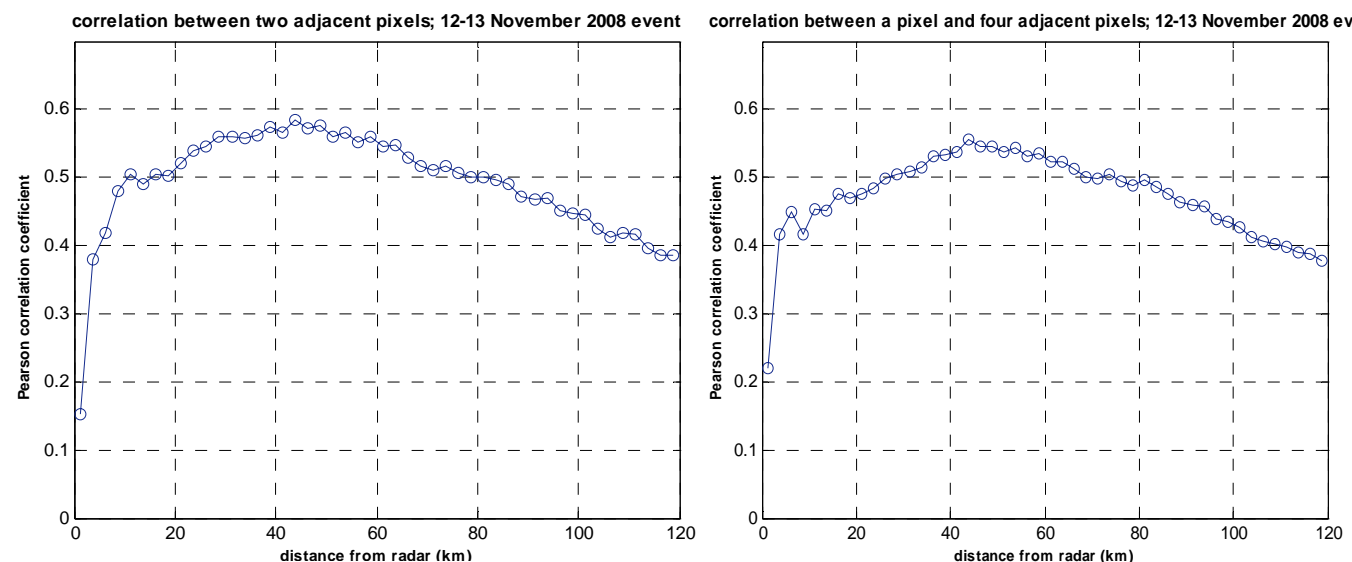

HESSD

$7,5171-5212,2010$

Comparison between radar and rain gauges data at different distances

S. Sebastianelli et al.

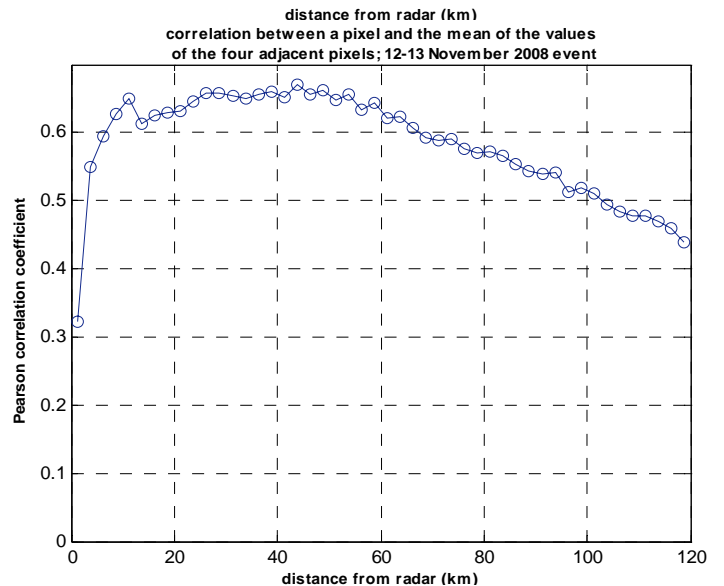

Title Page

Abstract Introduction

Conclusions

References

Tables

Figures

14

4

Back

Close

Full Screen / Esc

Fig. 4. Correlation between adjacent pixels estimated using the three methods abovementioned as a function of the distance from radar for the rainfall event of the 12-13 November 2008.

Printer-friendly Version

Interactive Discussion 

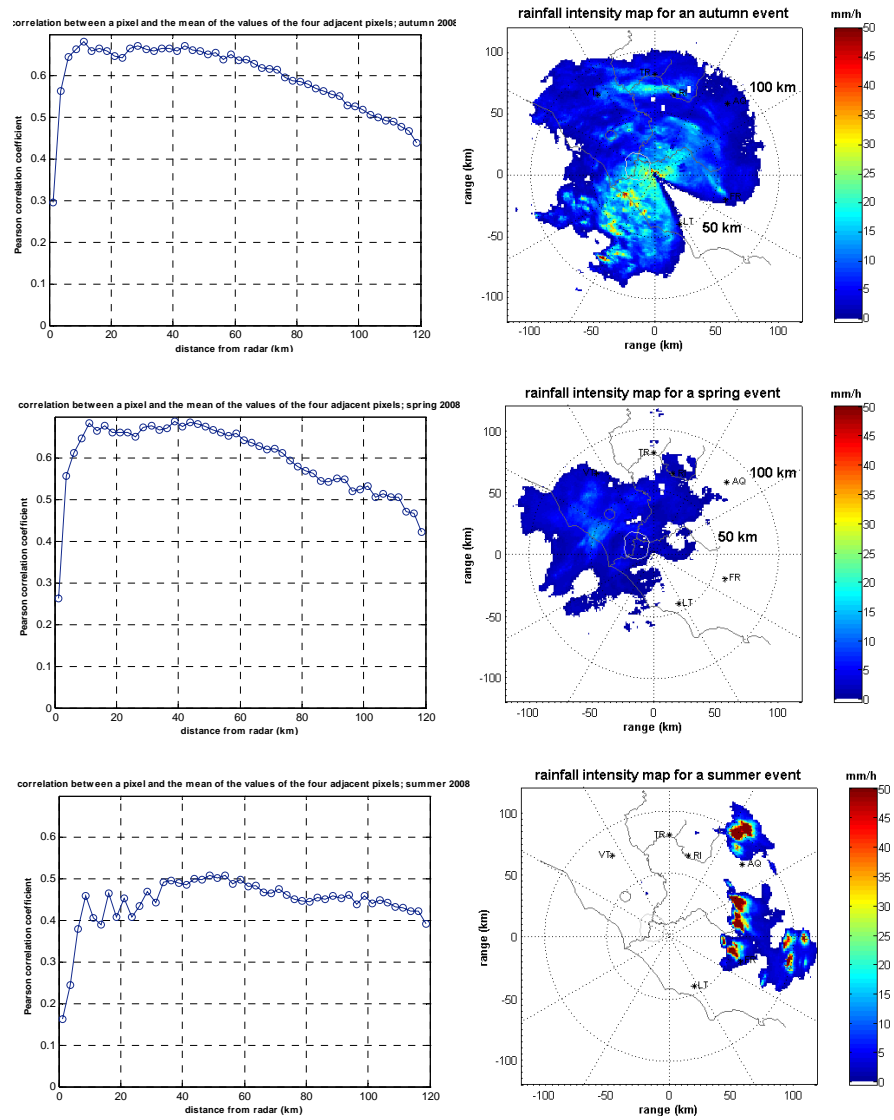

Fig. 5. Plots representing the correlations between adjacent pixels as a function of distance from radar estimated using the third method for the whole of the rainfall events in autumn 2008 (above, to the left), in spring 2008 (above, to the right) and in the summer 2008 (down), coupled with a PPI of an autumn rainfall event, a PPI of a spring rainfall event and a PPI of a summer rainfall event respectively.
HESSD

$7,5171-5212,2010$

Comparison between radar and rain gauges data at different distances

S. Sebastianelli et al.

Title Page

Abstract

Introduction

Conclusions

References

Tables

Figures

14

$\rightarrow$

4

Back

Close

Full Screen / Esc

Printer-friendly Version

Interactive Discussion 


\section{HESSD}

$7,5171-5212,2010$

correlation between a pixel and the mean of the values of the four adjacent pixels; year 2008

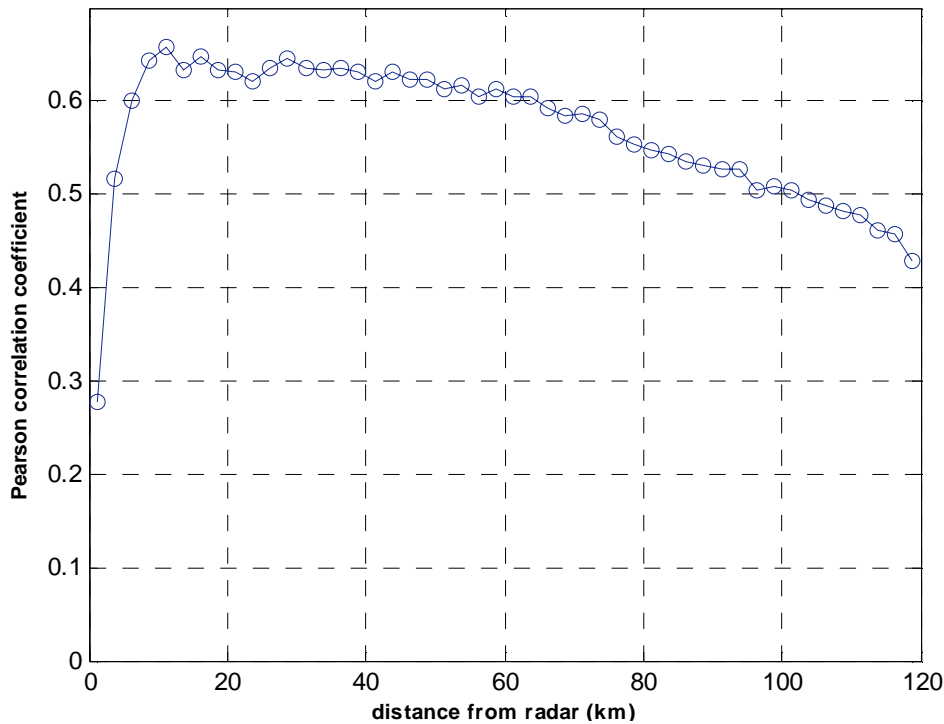

Fig. 6. Correlation between adjacent pixels as a function of distance from radar estimated by utilizing the third method for the whole of the rainfall events in the year 2008.
Comparison between radar and rain gauges data at different distances

S. Sebastianelli et al.

Title Page

Abstract Introduction

Conclusions

References

Tables

Figures

14

$\rightarrow$ I

4

Back

Close

Full Screen / Esc

Printer-friendly Version

Interactive Discussion 

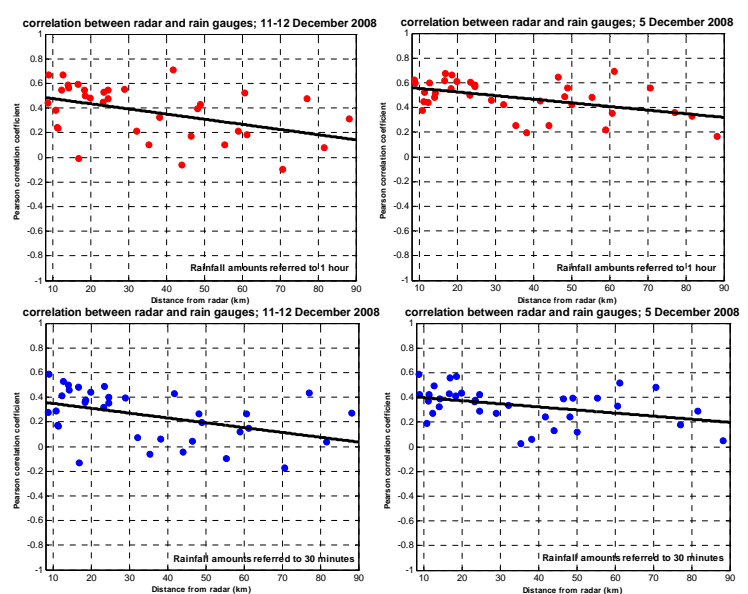

HESSD

$7,5171-5212,2010$

Comparison between radar and rain gauges data at different distances

S. Sebastianelli et al.
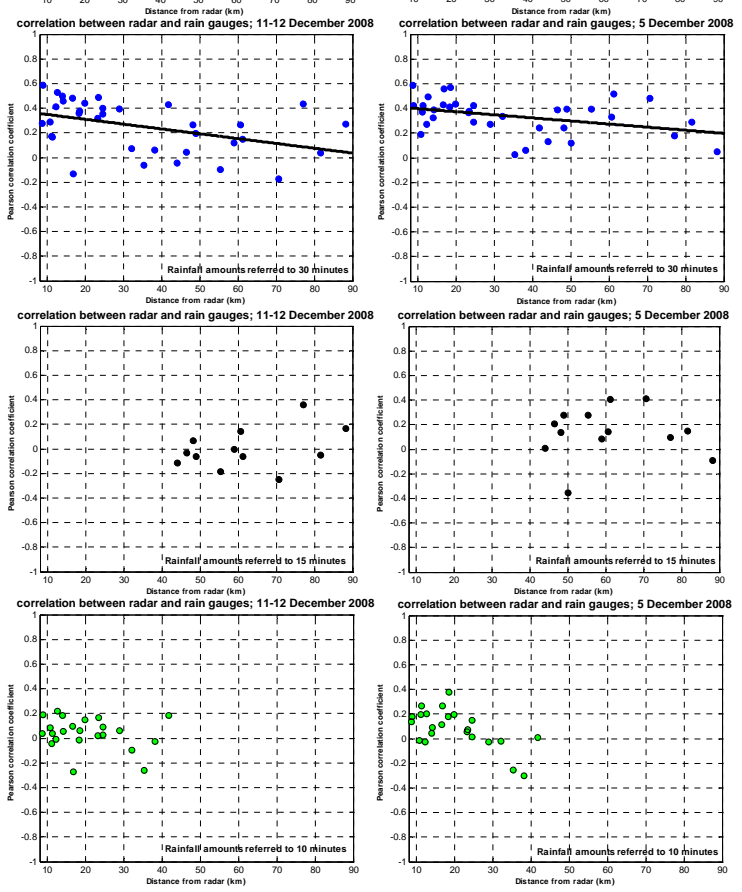

Title Page

Abstract Introduction

Conclusions

References

Tables

Figures
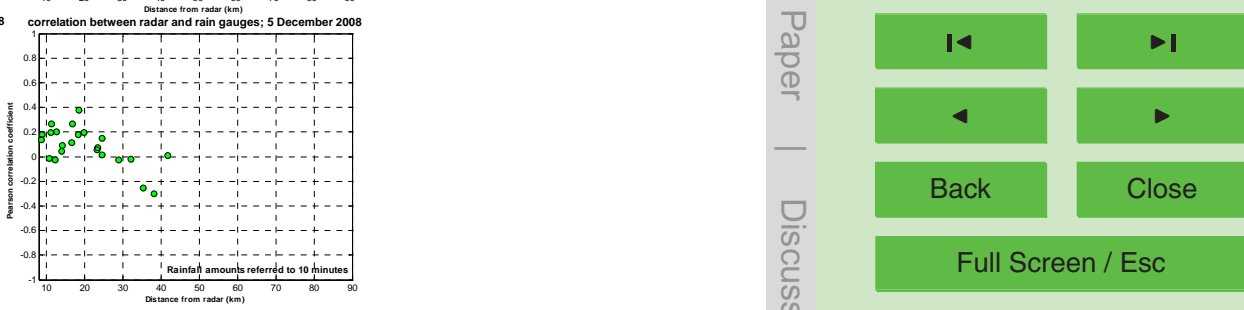

Full Screen / Esc

Fig. 7. Trend of the Pearson correlation coefficient when increasing the distance from radar estimated, for the rainfall events indicated in figure, by utilizing time intervals of $1 \mathrm{~h}$ (in red), $30 \mathrm{~min}$ (in blue), $10 \mathrm{~min}$ (in green) and $15 \mathrm{~min}$ (in black). 

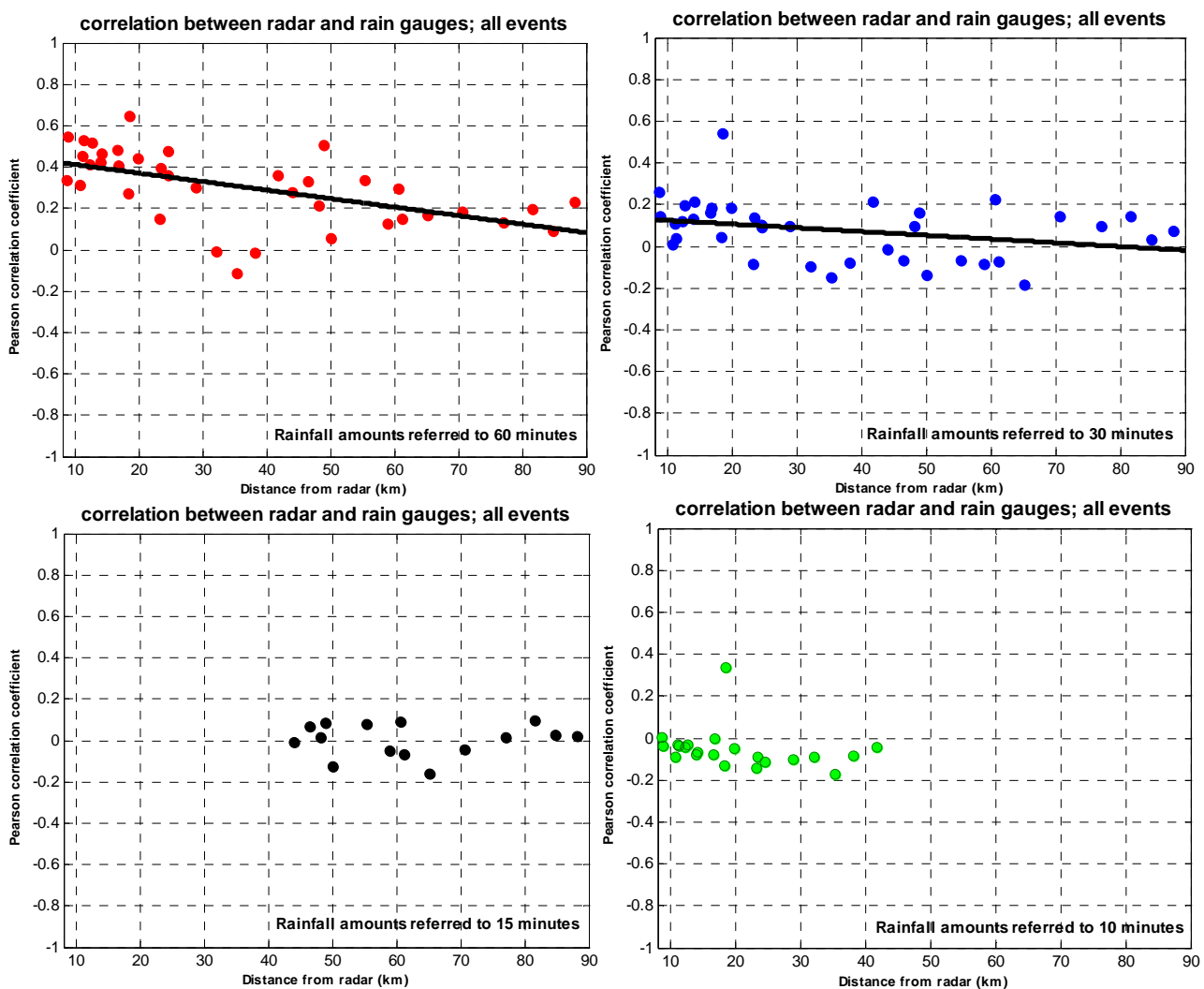

Fig. 8. Trend of the Pearson correlation coefficient when increasing the distance from radar estimated for all the rainfall events considered in this study, by utilizing time intervals of $1 \mathrm{~h}$ (in red), $30 \mathrm{~min}$ (in blue), $10 \mathrm{~min}$ (in green) and $15 \mathrm{~min}$ (in black).

\section{HESSD}

$7,5171-5212,2010$

\section{Comparison between radar and rain gauges data at different distances}

S. Sebastianelli et al.

\section{Title Page}

\section{Abstract}

Introduction

Conclusions

References

Tables

Figures

14

$>$ I

4

Back

Close

\section{Full Screen / Esc}

Printer-friendly Version

Interactive Discussion 

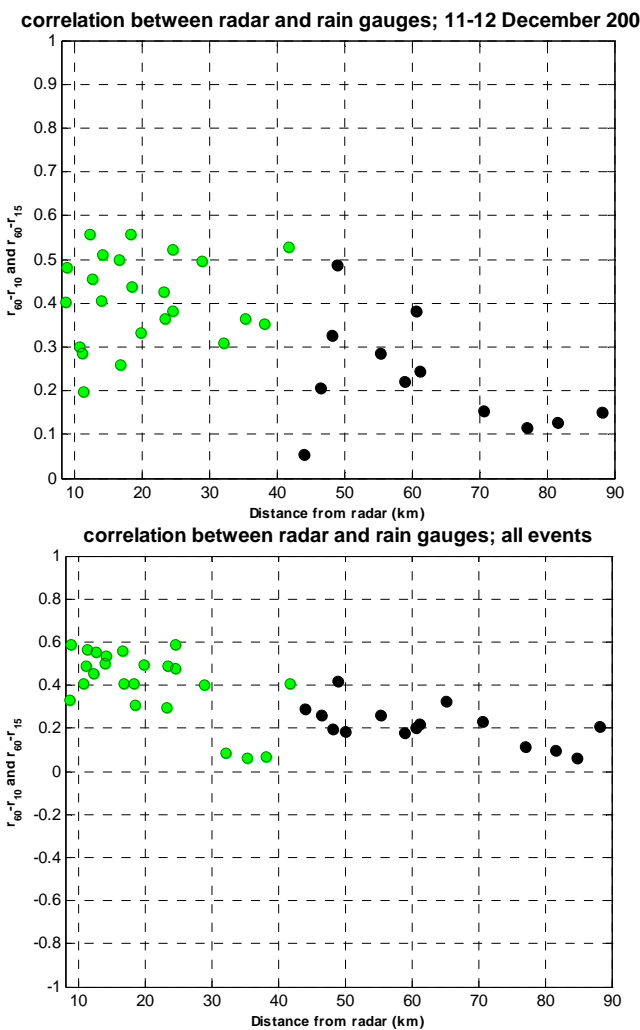

Fig. 9. Trend of the differences between Pearson coefficient values relative to $1 \mathrm{~h}$ time aggregations and $10 \mathrm{~min}$ time aggregations (in green) and trend of the differences between Pearson coefficient values relative to $1 \mathrm{~h}$ time aggregations and $15 \mathrm{~min}$ time aggregations (in black) when increasing the distance from radar estimated, for the rainfall events of 11-12 December 2008 (up to the left) and of 5 December 2008 and for all the events considered in this study (down).

\section{HESSD}

$7,5171-5212,2010$

Comparison between radar and rain gauges data at different distances

S. Sebastianelli et al.

\section{Title Page}

\section{Abstract}

Introduction

Conclusions

References

Tables

Figures

14

$>$ I

4

Back

Close

\section{Full Screen / Esc}

Printer-friendly Version

Interactive Discussion 


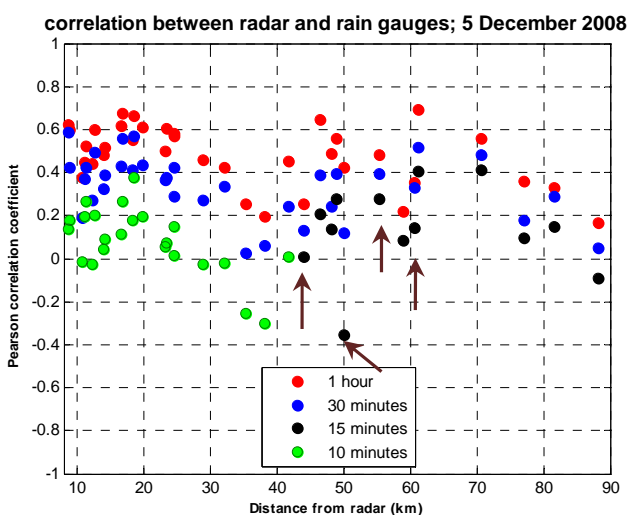

correlation between radar and rain gauges; 25-26 November 2008

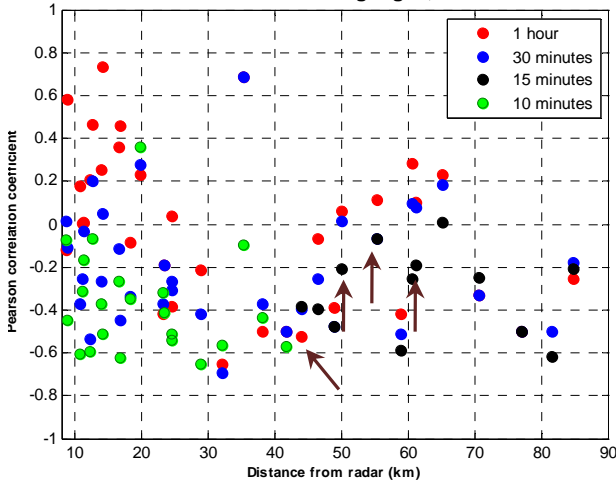

correlation between radar and rain gauges; 11-12 December 2008

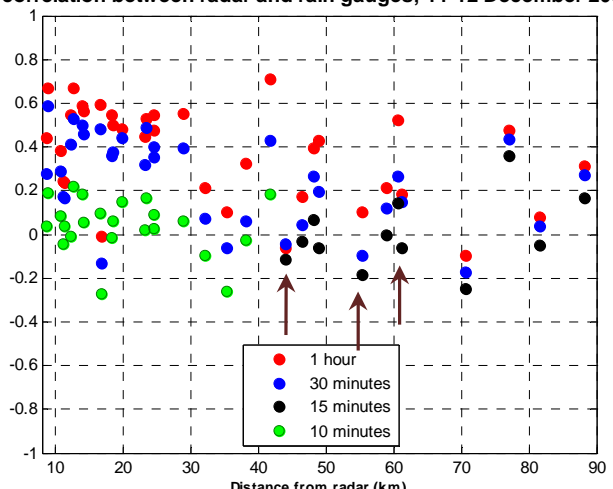

correlation between radar and rain gauges; all events

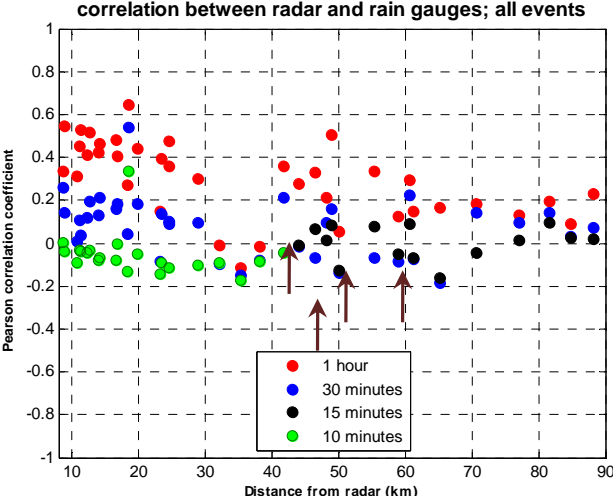

HESSD

$7,5171-5212,2010$

Comparison between radar and rain gauges data at different distances

S. Sebastianelli et al.

\section{Title Page}

\section{Abstract}

Introduction

Conclusions

References

Tables

Figures

14

$\rightarrow$

4

Back

Close

\section{Full Screen / Esc}

Printer-friendly Version

Interactive Discussion 

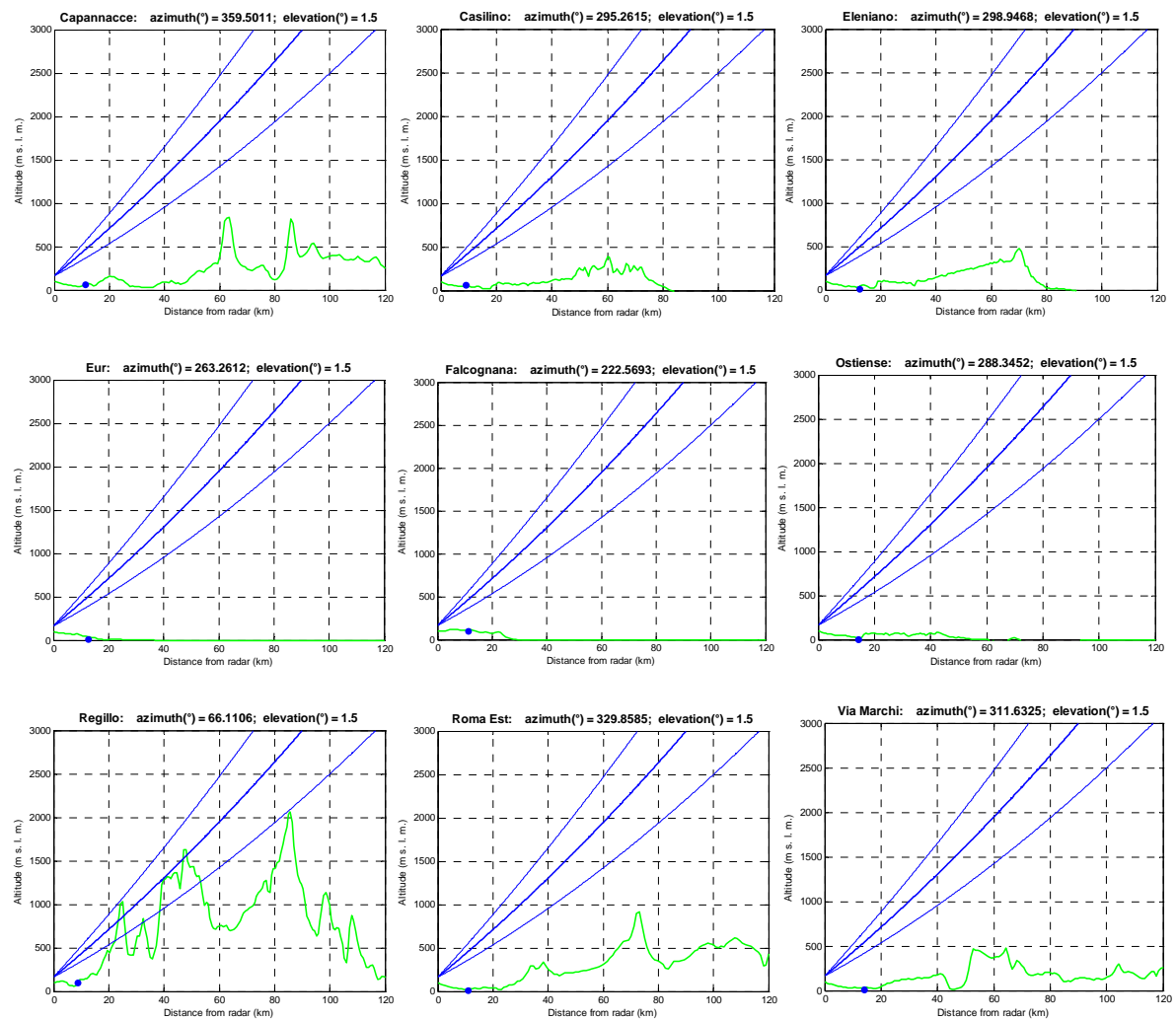

Fig. 11. Visibility of the radar beam (in blue) in relation to the altimetrical profile (in green), the distance from radar of the rain gauge (represented by the dot in blue) and the elevation angle for the pixels where belong the rain gauges situated in the roman area; each plot in figure shown the absence of non meteorological target in the beam width for the rain gauges considered.

\section{HESSD}

$7,5171-5212,2010$

\section{Comparison between radar and rain gauges data at different distances}

S. Sebastianelli et al.

\section{Title Page}

\section{Abstract}

Introduction

Conclusions

References

Tables

Figures

14

$\rightarrow I$

4

Back

Close

\section{Full Screen / Esc}

Printer-friendly Version

Interactive Discussion 

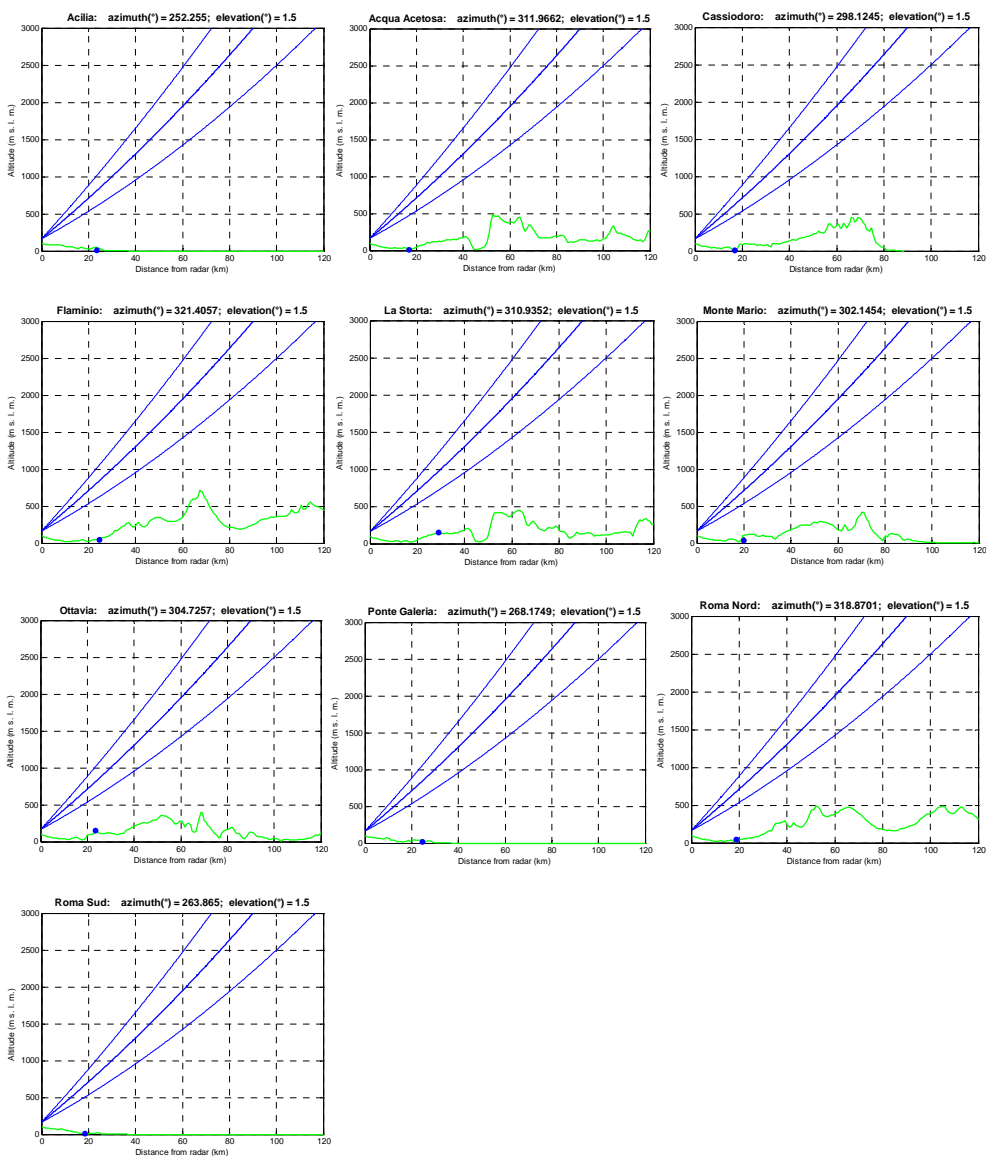

Fig. 12. Visibility of the radar beam (in blue) in relation to the altimetrical profile (in green), the distance from radar of the rain gauge (represented by the dot in blue) and the elevation angle for the pixels where belong the rain gauges at a distance of about $20-30 \mathrm{~km}$ from radar; each plot in figure shown the absence of non meteorological target in the beam width for the rain gauges considered.

5209

\section{HESSD}

$7,5171-5212,2010$

\section{Comparison between radar and rain gauges data at different distances}

S. Sebastianelli et al.

\section{Title Page}

Abstract Introduction

Conclusions

References

Tables

Figures

14

$\rightarrow I$

4

Back

Close

Full Screen / Esc

Printer-friendly Version

Interactive Discussion 

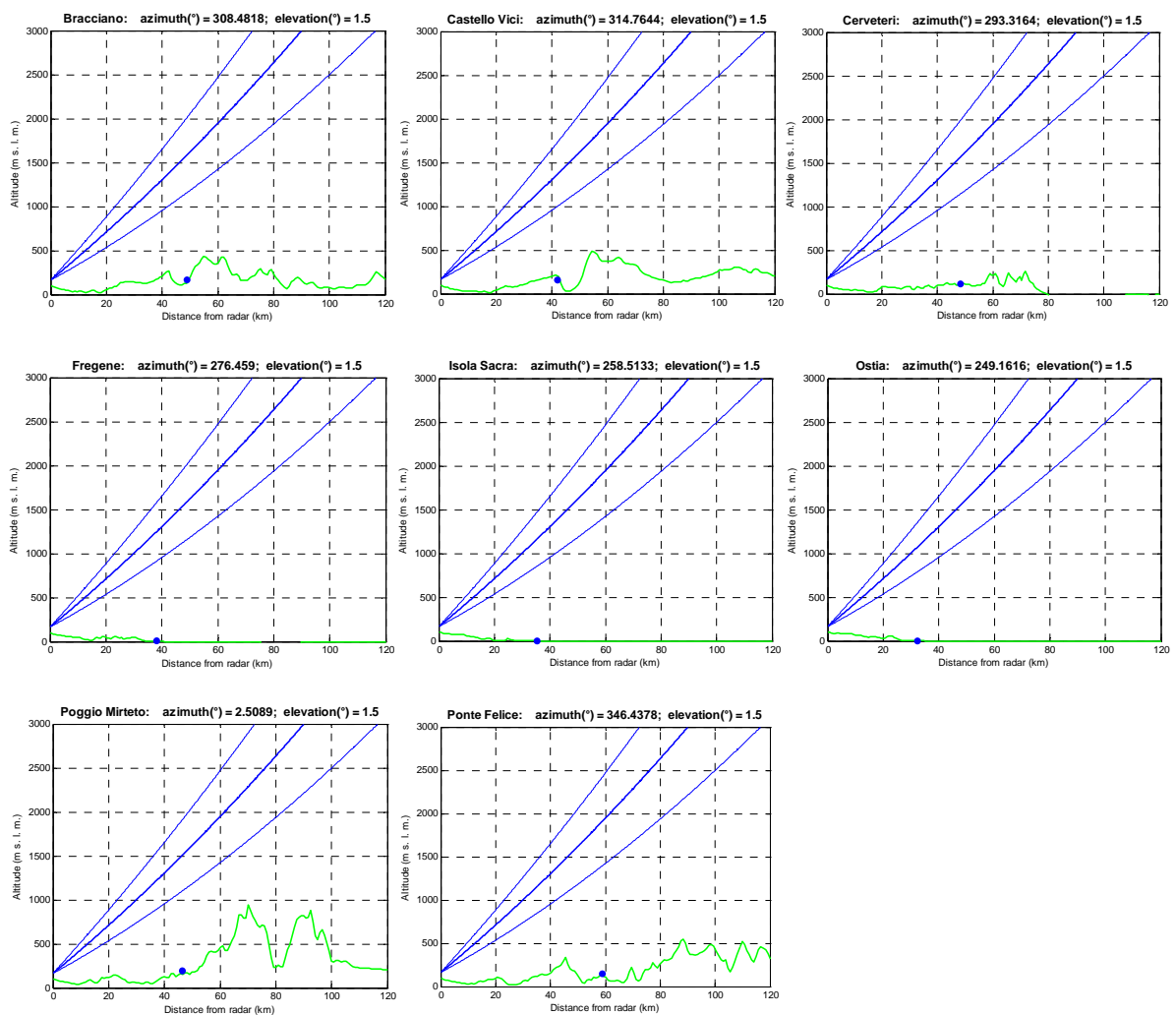

Fig. 13. Visibility of the radar beam (in blue) in relation to the altimetrical profile (in green), the distance from radar of the rain gauge (represented by the dot in blue) and the elevation angle for the pixels where belong the rain gauges at a distance ranged from 30 to $60 \mathrm{~km}$ from radar. Each plot in figure shown the absence of non meteorological target in the beam width for the rain gauges considered.

\section{HESSD}

$7,5171-5212,2010$

\section{Comparison between radar and rain gauges data at different distances}

S. Sebastianelli et al.

\section{Title Page}

\section{Abstract}

Introduction

Conclusions

References

Tables

Figures

14

$\rightarrow I$

4

Back

Close

\section{Full Screen / Esc}

Printer-friendly Version

Interactive Discussion 


\section{HESSD}

$7,5171-5212,2010$
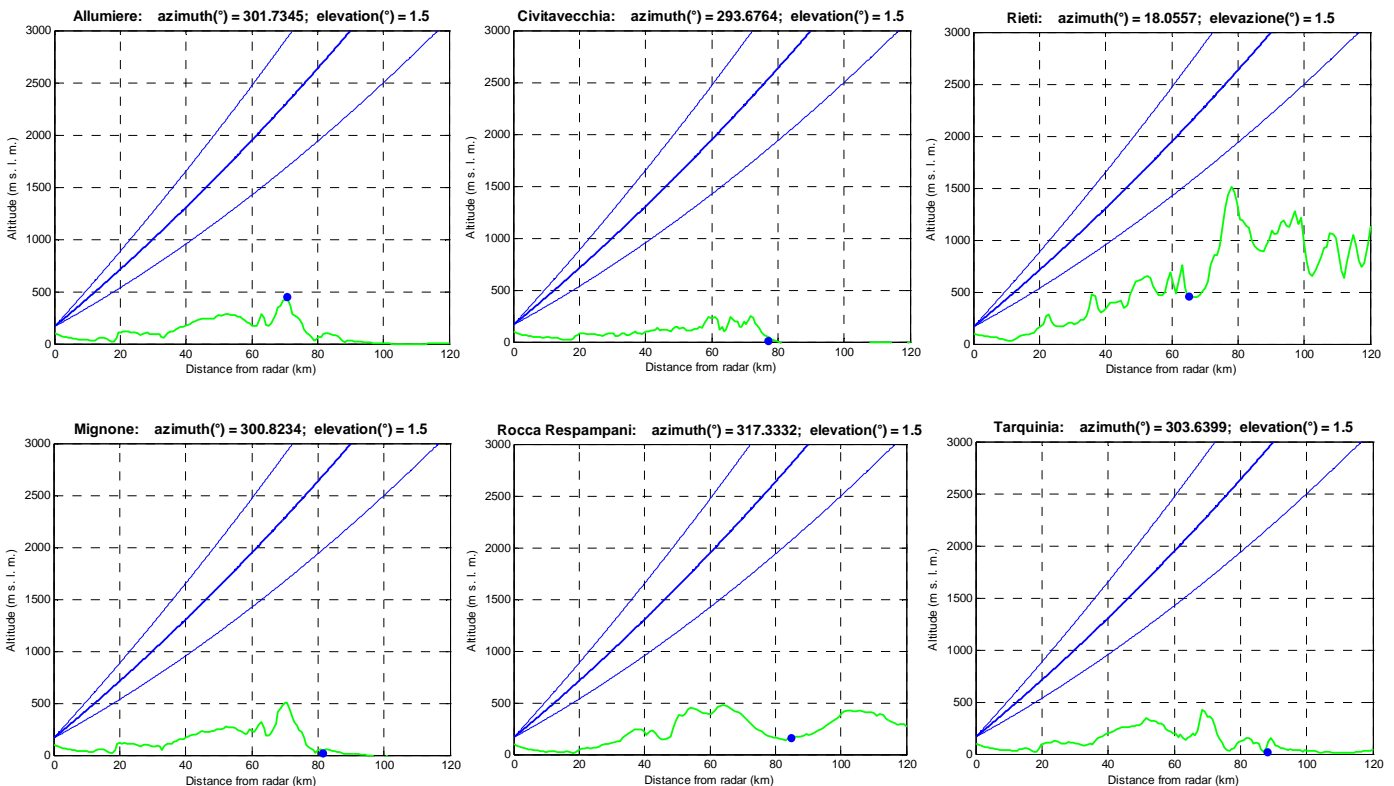

Fig. 14. Visibility of the radar beam (in blue) in relation to the altimetrical profile (in green), the distance from radar of the rain gauge (represented by the dot in blue) and the elevation angle for the pixels where the rain gauges at a great distance from radar belong; each plot in figure shown the absence of non meteorological target in the beam width for the rain gauges considered.

Title Page

Abstract

Introduction

Conclusions

References

Tables

Figures

14

$\rightarrow$

4

\section{Comparison between radar and rain gauges data at different distances}

S. Sebastianelli et al.

Back

Close

Printer-friendly Version

Interactive Discussion 
HESSD

$7,5171-5212,2010$

Comparison between radar and rain gauges data at different distances

S. Sebastianelli et al.
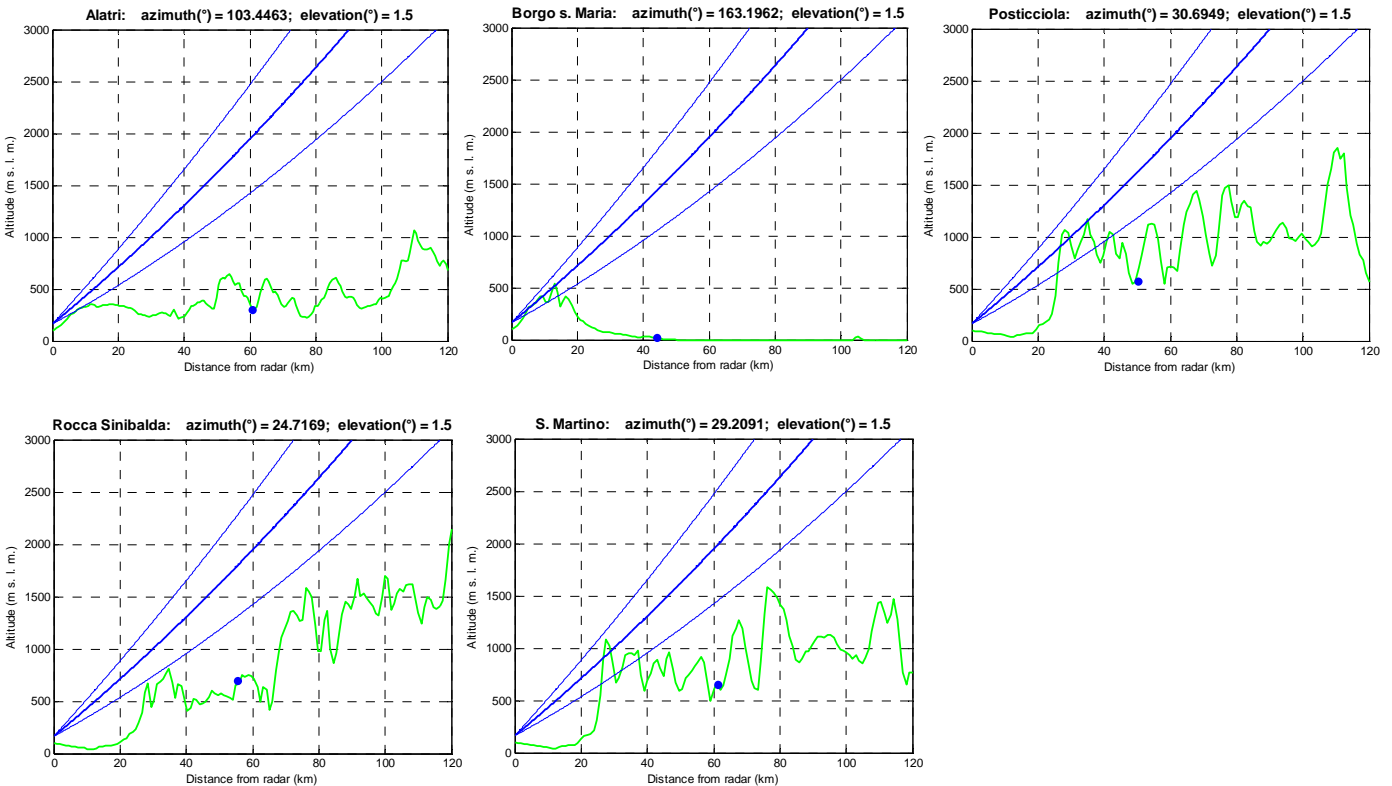

Fig. 15. Cases of beam-blocking total or partial for the pixels where belong some of the rain gauges (represented by the dots in blue) utilized in this work.
Title Page

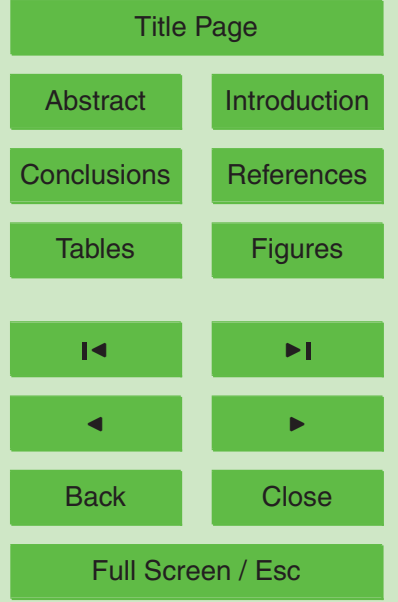

Printer-friendly Version

Interactive Discussion 